\title{
LA VARIACIÓN DENOMINATIVA EXPLICITA: PROPUESTA DE TIPOLOGÍA DE CASOSi
}

\author{
María Mercedes Suárez de la Torre*
}

ABSTRACT: The denominative variants, represented by two or more lexical units, display, one with respect to the other, some difference when referring to the same concept. In this sense, we realize that the denominative variants keep, at the same time, a relationship of equivalence and difference since we do not find in any case of denominative variation a complete semantic identity among them. This relationship of equivalence that denominative variants maintain among themselves, and that is, partial or relative, is explicitly stated through the discursive production and more specifically by means of the treatment procedures (Gülich \& Kotschi 1995). In this paper, the mechanism of analysis used for the study of the explicit denominative variants and for the analysis of its semantic traits will be explained. Also, a proposal of a case typology of explicit denominative variation and the results obtained in the detailed analysis of each of the types and subtypes proposed will be presented.

KEYWORDS: Denominative variation. Explicit denominative variation. Case typology of variation. Explicit denominative markers. Discourse production. Partial equivalente. Relative equivalence. Semantic traits. Terminological unit.

\section{INTRODUCCIÓN}

La diversidad de las lenguas se manifiesta mediante diferentes fenómenos, entre los que destaca el fenómeno de la variación lingüística. En este artículo atenderemos a un tipo de variación lingüística: la variación denominativa, es decir, la presencia de formas léxicas distintas para referirse a un mismo concepto. Específicamente abordaremos el estudio de un tipo de variación denominativa que hemos denominado variación denominativa explícita (para cuya denominación utilizaremos también la sigla VDE), la que se da a través de marcadores discursivos que vehiculan equivalencia.

La noción de variación denominativa en el interior de los textos especializados, entendida como la presencia de formas distintas para referirse a un mismo concepto, constituye un tema polémico en el ámbito de la terminología. Los planteamientos más tradicionales de la terminología (Wüster 1985 y Arntz y Picht 1995) han defendido la idea de la biunivocidad, según la cual cada concepto está adscrito a una única denominación y viceversa. Por el contrario, la Teoría Comunicativa de la Terminología (Cabré 1999) parte de la base que la variación denominativa constituye un hecho real de la comunicación especializada y, por tanto, se presenta en textos construidos por especialistas.

La controversia suscitada en torno a este fenómeno nos ha llevado a enmarcar este trabajo en un enfoque comunicativo de la terminología (Cabré 1999, 2003): por un lado, porque considera el texto como eje central para llevar a cabo el análisis de los términos, y, por otro lado, porque permite una descripción más detallada de las variantes denominativas como unidades del lenguaje natural que encuentran su explicación mediante la gramática de la lengua en que se usan. Del enfoque comunicativo de la terminología se desprende el siguiente supuesto teórico:

Las variantes denominativas, representadas por dos o más unidades léxicas, presentan la una respecto a la otra alguna diferencia haciendo referencia a un mismo concepto. En este sentido, nos damos cuenta de que las variantes denominativas mantienen al mismo tiempo una relación de equivalencia y diferencia ya que no encontramos en ningún caso de variación denominativa una identidad semántica completa entre las variantes.

A partir de este supuesto, proponemos el estudio de las variantes denominativas en el texto desde una perspectiva semántica, y específicamente mediante el análisis de los componentes del contenido semántico de las variantes (Nida 1975, Gülich y Kotschi 1995). Para realizar este tipo de análisis, en primer lugar se deben identificar los rasgos "necesarios y suficientes" que permitan diferenciar el contenido semántico de una unidad en relación con otra u otras unidades que están compitiendo por ocupar un lugar en un mismo territorio semántico. En segundo lugar, es necesario indagar los rasgos o componentes comunes para llegar a comprender el significado o contenido.

Con el fin de determinar estos componentes semánticos, tuvimos en cuenta el contexto de aparición de cada variante denominativa, porque suministra una serie de pistas que ayudan a establecer de una manera más eficaz las coincidencias y diferencias entre los contenidos. Además del contexto, utilizamos también otros recursos para desglosar los componentes semánticos de las variantes

\footnotetext{
* María Mercedes Suárez de la Torre. Universidad Autónoma de Manizales Instituto de idiomas. Grupo de Investigación CITERM.
} 
denominativas, a saber: especialistas en el dominio, glosarios y diccionarios especializados y textos electrónicos que desarrollan el contenido de una unidad léxica con mayor profundidad.

Para llevar a cabo este análisis, hemos constituido un corpus de textos especializados pertenecientes al dominio del genoma humano, tomados de la revista Scientific American ${ }^{i i}$.

\section{ANÁLISIS DE LOS COMPONENTES SEMÁNTICOS DE LAS VARIANTES DENOMINATIVAS EXPLÍCITAS}

Nida (1975) subraya la importancia del contraste para establecer el contenido lingüístico de las unidades léxicas. Todo contenido tiene razón de ser si se puede contrastar con otro con el que guarda alguna relación de contigüidad. En este sentido, Nida afirma que para determinar los componentes o rasgos del contenido central de una unidad léxica es necesario contrastarlo con contenidos expresados por otras formas que ocurren en un mismo dominio semántico ya que éstas comparten ciertos aspectos de parentesco.

"Common components are those shared by any semantic domain. As such they serve to "define" the domain, in the sense that they prescribe its boundaries by stating the essential features of the included meanings". (Nida 1975:33).

Estos mismos componentes de contenido común y diferencial mencionados por Nida son tratados por Gülich \& Kotschi (1995) desde la perspectiva de la producción discursiva como relación de equivalencia y relación de diferencia. Según estos autores, entre dos unidades alternativas para un mismo concepto (expresión de referencia y expresión de tratamiento) existe una relación semántica que puede caracterizarse simultáneamente en dos perspectivas opuestas: de equivalencia y de diferencia. Ambas relaciones pueden estar presentes a diferentes niveles.

La relación de equivalencia, entendida en sentido lato como gradual, incluye relaciones entre expresiones que comparten sólo una base sémica limitada, que puede, por consiguiente, establecer equivalencia sólo en "sentido parcialmente denotativo" (Gülich \& Kotschi 1995).

Sin embargo, para las funciones discursivas cruciales, esta coincidencia mínima es suficiente para determinar que se da la relación de equivalencia. En relación a dos constituyentes (X e Y) un emisor puede referirse a $\mathrm{Y}$ con la misma unidad con la que se ha referido a $\mathrm{X}$ teniendo en cuenta que el referente debe ser identificado tanto con $\mathrm{X}$ como con $\mathrm{Y}$.

En la relación de diferencia, cualquier unidad léxica alternativa (expresión de tratamiento en términos de Gülich \& Kotschi), contiene algo nuevo, un elemento de cambio de la progresión comunicativa. En este sentido, Gülich \& Kotschi afirman que como regla general se presenta algún tipo de cambio.

Desde nuestra perspectiva hemos adoptado este mecanismo de análisis propuesto tanto por Nida como por Gülich \& Kotschi, con el fin de establecer la relación semántica que se presenta entre las variantes denominativas explícitas.

"Certain sets of related meanings appear to be so close to one another that one cannot determine whether or not they are complete synonyms. In such instances it may seem impossible to determine just how such meanings may differ from one another" (Nida 1975:102)

Tal y como mencionamos anteriormente, para determinar estos componentes semánticos tuvimos en cuenta ante todo el contexto de aparición de cada variante denominativa.

El contexto es relevante en este tipo de análisis no sólo porque sirve para determinar los componentes, sino porque permite separar, sobre la base de la detección de rasgos o características particulares, ciertos contenidos de otros que aparentemente están en una relación de solapamiento, esto es, contenidos utilizados para hacer referencia a los mismos objetos o eventos.

Aunque dicho contexto no suministra información enciclopédica sobre los referentes, suministra una serie de pistas que ayudan a establecer, de una manera más eficaz, las coincidencias y diferencias entre los contenidos.

Pero además del contexto, hemos utilizado también otros recursos para desglosar los componentes semánticos de las variantes denominativas. Dichos recursos son los siguientes:

a) Colaboración de especialistas en el dominio del genoma humano: en este caso, la intervención del experto es de gran utilidad porque permite entrar a la unidad léxica por la puerta del concepto $^{\text {iii }}$. Las aportaciones del experto, en este sentido, enriquecen el análisis no sólo desde el punto de vista semántico sino también pragmático dado que sólo el especialista puede en un determinado momento identificar el registro, el uso específico de la unidad léxica en cada situación comunicativa y las restricciones de uso según cada grupo de investigación.

b) Consulta de definiciones registradas en glosarios y diccionarios especializados en el dominio del genoma humano: este tipo de recurso es necesario y útil porque permite 
acceder a la unidad léxica por la puerta del concepto desglosado en la definición. Aunque somos conscientes que se trata de una fuente estática, permite detectar rasgos o componentes del contenido que el experto puede pasar por alto en el dominio especializado en determinado momento.

c) Consultas electrónicas de textos que desarrollan el contenido de una unidad léxica con mayor profundidad: este tipo de recurso es útil porque permite aunar ambas fases (consulta de expertos y glosarios). La unión de estos dos factores contribuye de manera eficaz a la descomposición de los componentes y sirve de gran apoyo cuando carecemos de los dos recursos mencionados anteriormente.

A continuación presentamos el análisis de tres ejemplos de nuestro corpus: VDE2.

Nos referiremos a las variantes denominativas explícitas por su orden de aparición: VDE1 y

(1) INCIDENCE OF HYPERTENSION, or chronic high blood pressure, was assessed by the authors in Africans as well as in people of African descent in the U.S. and the Caribbean. The rate dropped dramatically from the U.S. across the Atlantic to Africa (graph), and the difference was most pronounced between urban African-Americans (below, right) and rural Nigerians (below, left).

En este fragmento encontramos dos variantes en relación de equivalencia: hypertension y chronic high blood pressure, unidas mediante el marcador or.

En el plano del contenido observamos que la primera variante denominativa (VDE1) hypertension está constituida por el prefijo hyper que da la idea de «exceso». Hypertension hace referencia a la «tensión arterial superior a la normal». En esta variante, el tipo de tensión de la que se habla —arterial一 es implícita.

En la segunda variante denominativa (VDE2) chronic high blood pressure encontramos una serie de adjetivos que a la idea de exceso (high), añaden la idea de enfermedad habitual de larga duración, mediante la utilización del adjetivo chronic. Además, en esta variante el tipo de tensión se hace explícita (blood pressure - presión sanguínea).

Este tipo de información permite deducir que los componentes que comparten las dos variantes son la idea de exceso y de enfermedad (implícita en ambas variantes). De ello podemos deducir que presentan entre ellas una relación de equivalencia. En tanto que los componentes diferenciales que distinguen a ambas expresiones se establecen a partir de la presencia de los adjetivos chronic y blood que traen consigo la idea de larga duración y el tipo de tensión. El siguiente esquema nos permite ver de manera más detallada los componentes comunes y diferenciales de las variantes ${ }^{\text {iv }}$ :

\begin{tabular}{|l|c|c|}
\cline { 2 - 3 } \multicolumn{1}{c|}{} & Hypertension (VDE1) & Chronic high blood pressure (VDE2) \\
\hline Idea de exceso & + & + \\
\hline Idea de enfermedad & + & + \\
\hline Duración & - & + \\
\hline Tipo de tensión & - & + \\
\hline
\end{tabular}

En este primer ejemplo observamos claramente que el autor considera importante situar al destinatario en otro nivel del conocimiento mediante el uso de una explicación. Esta explicación hace posible un cambio de registro, es decir, que de una unidad terminológica condensada [hypertension], el emisor pasa a utilizar una unidad terminológica paratáctica o analítica, más transparente para un destinatario menos experto [Chronic high blood pressure].

Un aspecto importante a observar es el orden de aparición de las variantes. En este ejemplo, la primera es la unidad condensada hypertension y la segunda es la unidad desarrollada Chronic high blood pressure. Tal y como veremos más adelante, este orden de aparición tiene consecuencias cognitivas importantes con respecto a la planificación del emisor y a las consecuencias interpretativas del receptor.

Otro aspecto importante que podemos extraer del fragmento que analizamos es la función que cumple el marcador discursivo or en relación a las dos variantes. Este marcador, que tiene la capacidad de asociar y disociar al mismo tiempo, es un marcador bastante neutro, ya que establece un vínculo de disyunción entre las variantes que se puede interpretar ya sea como una relación de inclusión (equivalencia), ya sea de exclusión (no equivalencia).

Veamos el segundo ejemplo:

(2) Early work by our group demonstrated that scissors can inactivate a selected part of a chromosome in dividing cells - specifically, a region containing genes that control construction of a nuclear organelle known as a nucleolus.

En este fragmento, si analizamos las variantes denominativas en cuestión desde el punto de vista formal, observamos que en la formación de la VDE2 se han utilizado elementos morfoléxicos que 
posibilitan la condensación de dicha variante. Así, la variante denominativa nucleolus, está formada por el primer constituyente de nuclear y el segundo constituyente de organelle, que equivale a organulus en latín.

El uso de este recurso morfoléxico (tomar los dos constituyentes para formar una sola unidad) permite al autor, tal y como veremos más adelante, presentar supuestamente una misma información de manera más concisa.

En el plano del contenido, observamos que las dos variantes denominativas comparten los componentes que encierran el adjetivo nuclear y el nombre nucleolus [nucle + olus] puesto que ambos tienen desde el punto de vista etimológico la misma raíz (del latín nucleus 'parte comestible de la nuez o la almendra, y, por extensión, parte central'); esto es, un objeto X "situado en el interior del núcleo de una célula".

En la primera variante observamos que aparecen también los componentes que encierra el nombre organelle; es decir, que además de la idea de ubicación (parte central - dentro del núcleo de la célula), mediante organelle se introduce la idea de "cuerpo adherido a la membrana".

La variante nuclear organelle comparte con la variante nucleolus los componentes de ubicación (situada en el interior del núcleo de la célula) y composición (unidad estructural); pero se diferencia en cuanto a la característica propia de VDE1 (idea de adhesión a la membrana). Así pues, tenemos que los componentes comunes presentes en las dos variantes son la ubicación y la composición, mientras que el componente diferencial viene dado por la condensación del componente presente en VDE1 que desaparece en VDE2: la característica específica de [organelle]. Estos componentes comunes y diferenciales se pueden resumir de la siguiente forma:

\begin{tabular}{|l|c|c|}
\cline { 2 - 3 } \multicolumn{1}{c|}{} & nuclear organelle & nucleolus \\
\hline Ubicación & + & + \\
\hline Composición & + & + \\
\hline Característica & + & - \\
\hline
\end{tabular}

En este segundo ejemplo, contrario al primero, el autor presenta de manera más condensada su conocimiento, ya que, de una variante más desarrollada y, en principio, más accesible al público no especialista (nuclear organelle) pasa a utilizar una variante más condensada (nucleolus). A nuestro modo de ver, esto hace que el discurso del especialista pase de un conocimiento más explícito (más accesible) a un conocimiento más conciso (menos accesible).

Consideramos que known as es un marcador discursivo, indicador de las operaciones metalingüísticas explícitas (OME) del lenguaje, que permite que ambas variantes denominativas sean presentadas como válidas y aceptadas en el dominio del genoma humano por el mero hecho de ser introducidas como equivalentes (Bach et al., 2002).

Veamos el tercer ejemplo:

(3) TWO NEURONS MEET at a junction called a synapse. A leading hypothesis of how memories form involves proteins called NMDA receptors, which sit on the surfaces of postsynaptic cells.

En este fragmento encontramos dos variantes en relación de equivalencia: junction y synapse, unidas mediante el marcador called.

Desde el punto de vista del contenido observamos que tanto junction como synapse comparten la idea de unión. Idea que se infiere del contexto no sólo por la VDE1 junction sino por la presencia del verbo meet (encontrar, reunirse o contactar con). No obstante, la VDE2 synapse abarca no sólo la idea de unión o contacto, sino también la idea de que la señal se transmite de un axón a una neurona.

La idea de señal transmisora aparece implícita en el contexto mediante la presencia de la unidad léxica neurons. En este ejemplo observamos que existe una relación de equivalencia y de diferencia entre las dos variantes, pero también percibimos una relación de inclusión puesto que los componentes de junction están incluidos en los componentes de la variante synapse, junction es hipónimo de synapse: relación genérico-específico.

"Included sets of meanings are distinct from one another by virtue of the fact that the included meanings have at least one or more diagnostic components than the meanings in which they are included." (Nida 1975:84)

Así, mediante el uso de la variante junction, el autor hace énfasis en sentido general a la idea de comunicación, unión, alianza, asociación o ayuda mutua para la consecución de un fin (a place, point, contact between two different regions). La variante synapse, aunque incluye cada una de las acepciones antes mencionadas, hace mayor énfasis a nivel más específico, en un punto de contacto con características especiales en el que intervienen las dendritas y las neuronas y cumple una función 
particular en el funcionamiento del cerebro. Por tanto, la VDE2 se convierte en una unidad con un contenido más especializado que el contenido de la VDE1.

El uso del marcador called en este ejemplo, sitúa la variante en un plano metalingüístico ya que permite al autor establecer una jerarquización (general-específico) entre las dos variantes, y muestra como los contenidos de dichas variantes pueden estar a distinto nivel en cuanto a la concordancia conceptual o semántica.

Observemos el siguiente esquema que resume lo anterior:

\begin{tabular}{|l|c|c|}
\cline { 2 - 3 } \multicolumn{1}{c|}{} & junction & synapse \\
\hline Idea de unión & + & + \\
\hline Señal transmisora & - & + \\
\hline Función en el cerebro & - & + \\
\hline
\end{tabular}

Los ejemplos analizados permiten reiterar que, en su uso real, las variantes denominativas mantienen al mismo tiempo una relación de equivalencia y de diferencia, dado que observamos cierta intersección entre algunos de los componentes del contenido pero también ciertas diferencias que hacen que no haya una identidad semántica entre ellas. También observamos como el marcador constituye una pieza clave para establecer dicha relación semántica.

En síntesis, un análisis minucioso de casos en que los mismos referentes pueden designarse a través de diferentes expresiones revela que existen importantes distinciones semánticas entre los contenidos de las variantes denominativas, aunque algunas veces dichas distinciones se presenten de manera muy sutil.

A continuación presentaremos de manera detallada nuestra propuesta de tipos de caso de variantes denominativas explícitas; dicha propuesta se da sobre la base del cambio semántico que mantienen las variantes denominativas entre sí. También analizaremos el importante papel que cumplen los marcadores en el momento de establecer la relación de equivalencia y diferencia que experimentan las VDE.

\section{ANÁLISIS DETALLADO DE LA TIPOLOGÍA DE CASOS DE VARIACIÓN DENOMINATIVA EXPLÍCITA}

Las unidades léxicas poseen un contenido dinámico y adquieren a menudo nuevos sentidos que pueden ser efímeros; o, por el contrario, pueden tener una buena aceptación, arraigarse en la lengua con el fin de competir con otros y, en el mejor de los casos, convertirse en sentidos nuevos y al menos por algún tiempo lograr una estabilidad (Diccionario de la lengua española Lema, entrada relacionada con el cambio semántico 2001: 298-300).

De esta manera, surgen en la lengua los cambios a nivel de contenido. Un cambio en el contenido se produce cuando el emisor percibe alguna conexión o similitud entre los contenidos de las unidades que entran a competir por lograr determinado estatus en el interior de la lengua.

Dicha similitud permite establecer una asociación no sólo entre los contenidos de las unidades, sino también entre sus formas. Además, para que esta asociación pueda darse, deben concurrir ciertos factores relacionados con las motivaciones del cambio: la semejanza y la contigüidad.

La semejanza se produce cuando existe similitud entre los contenidos o entre las formas de las dos unidades léxicas existentes. La contigüidad se produce cuando los dos contenidos hacen referencia a conceptos que están vinculados o cuando las formas aparecen una junto a la otra.

Cuando el cambio está motivado por la semejanza, la asociación de contenidos se materializa a través de la metáfora, y la asociación de las formas, mediante la etimología. Cuando, por el contrario, el cambio es motivado por la contigüidad, la asociación de los contenidos se materializa a través de la metonimia y la asociación de las formas, a través de la elipsis.

Las nociones de semejanza y contigüidad guardan una estrecha relación con la noción de equivalencia. Generalmente, la noción de equivalencia ha sido vista como una relación de identidad semántica total entre dos enunciados o expresiones.

No obstante, la convergencia al mismo tiempo de componentes comunes y diferenciales hace que veamos la noción de equivalencia desde una perspectiva diferente, en la que las unidades léxicas presentan a la vez rasgos semejantes y no semejantes, que conducen a establecer una equivalencia semántica. Dicha equivalencia semántica, en palabras de Fuchs (1982:53), se origina a partir de la existencia de un núcleo semántico común sobre el cual se introducen diferencias semánticas secundarias.

"Par ailleurs, selon le nombre et la nature des points de vue secondaires que deux expressions peuvent avoir en commun, en plus du noyau sémantique commun, il sera possible de caractériser un degré plus ou moins fort d'équivalence entre ces expressions" (Fuchs 1982:56). 
Cuando se producen estas diferencias semánticas, el contenido de las unidades léxicas puede experimentar cambios que se manifiestan mediante una expansión, una reducción o una alteración. Gülich \& Kotschi (1995) tratan estos cambios dentro de lo que ellos denominan "procedimientos de tratamiento" y establecen tres tipos de cambios: expansión, reducción y variación.

Según estos autores, la expansión se presenta cuando la expresión de tratamiento tiene una extensión formal más amplia que la expresión de referencia, de modo que uno o varios semas de la expresión de referencia se fraccionan de manera más o menos arbitraria en características individuales que, en la expresión de tratamiento, se representan mediante unidades linguiísticas independientes.

La reducción constituye el proceso contrario a la expansión debido a que los rasgos semánticos de una unidad más amplia se condensan en uno o más semas de la expresión de tratamiento.

La variación no engloba las características de la expansión, ni de la reducción y se detecta mediante la diversa organización secuencial de más o menos las mismas unidades.

Ciapuscio (1993) en sintonía con Gülich \& Kotschi, plantea estos mismos cambios como formas de reformulación. En su clasificación, Ciapuscio muestra como la reducción puede manifestarse de diferentes formas, esto es por supresión y condensación ${ }^{v}$.

En este artículo compartimos las ideas de Gülich \& Kotschi y Ciapuscio en relación a la expansión y la reducción, pero diferimos del cambio denominado variación porque, a nuestro modo de ver y tal y como lo plantean, los cambios semánticos se reducen a meros cambios en el orden de presentación secuencial de las expresiones de referencia y de tratamiento.

Este tipo de variación, planteado de esta forma, parece producirse no precisamente por cambios de tipo semántico-pragmático sino más bien por causas sintácticas. Debemos admitir que la propuesta de Ciapuscio, con respecto a la variación, está planteada desde otra perspectiva, pues su finalidad consiste en mostrar que estos cambios o desplazamientos tienen lugar en el paso del texto fuente a la noticia de divulgación. Así pues, la variación se trata como una transformación del vocabulario científico que abarca niveles superiores de enunciación.

El análisis de los materiales mediante los componentes semánticos de las VDE nos ha llevado a los siguientes tipos de casos:

\section{Tipo 1}

Este tipo se aplica a aquellos casos en que una unidad léxica condensada pasa a ser una unidad léxica más desarrollada y transparente, debido a que en la unidad léxica más desarrollada se añaden rasgos o componentes que no estaban presentes en la unidad léxica condensada.

Veamos algunos ejemplos:

(1) Injection of the hormone insulin once or several times a day helps the cells of diabetics to take up the sugar glucose (critical source of energy) from the blood.

En este ejemplo observamos que la unidad léxica sugar glucose (VDE1) hace referencia al azúcar de color blanco, cristalizable de sabor muy dulce, muy soluble en agua y poco soluble en alcohol que se halla presente en la miel, en la fruta y en la sangre de los animales.

La unidad léxica critical source of energy (VDE2) hace referencia a este mismo tipo de azúcar [glucose] descrito como una fuente de energía para las personas diabéticas. En este sentido, vemos que en VDE2 se añaden rasgos que no están presentes en VDE1: en VDE1 sugar glucose se mencionan los componentes del cuerpo sólido y su procedencia, mientras que en VDE2, además de los rasgos descritos, se añade una propiedad esencial de este componente - la glucosa es una fuente de energía.

\begin{tabular}{|l|l|l|}
\cline { 2 - 3 } \multicolumn{1}{c|}{} & sugar glucose & critical source of energy \\
\hline Componentes & + & + \\
\hline Procedencia & + & + \\
\hline Propiedad & - & + \\
\hline
\end{tabular}

(2) In terms of treatment, scientists have for more than three decades tried to find ways to sic the immune system on cancer-a tactic termed immunotherapy or vaccine therapy.

En el ejemplo 2 observamos la unidad léxica immunotherapy (VDE1) y la unidad vaccine therapy (VDE2), unidas mediante el marcador $o r$.

Desde el punto de vista del contenido vemos que en la VDE2 vaccine therapy se añaden rasgos que no están presentes en VDE1 immunotherapy: la immunoterapia hace referencia a la "administración gradual de una sustancia alérgica. Este proceso conduce a la reducción de los síntomas que pueden presentarse después de la exposición al alérgeno".

Vemos que la VDE1 hace énfasis en el proceso [administración de una sustancia alérgica], mientras que la VDE2 vaccine therapy, además de hacer referencia al proceso, añade el rasgo, mediante el 
uso de la unidad léxica vaccine, que permite ampliar el contenido y conocer la forma como se lleva a cabo el proceso, esto es, mediante un medicamento que se introduce en un organismo para preservarlo de una enfermedad -vacunas antialérgicas-.

En VDE1 está presente el rasgo que hace referencia al procedimiento, mientras en VDE2, además del procedimiento, encontramos un rasgo adicional que hace referencia al medicamento.

\begin{tabular}{|l|c|c|}
\cline { 2 - 3 } \multicolumn{1}{c|}{} & Immunotherapy & Vaccine therapy \\
\hline Procedimiento & + & + \\
\hline Medicamento & - & + \\
\hline
\end{tabular}

Tipo 2

Se observan también casos en que una unidad léxica desarrollada pasa a ser una unidad léxica más condensada, debido a que la unidad léxica desarrollada experimenta una reducción o condensación en sus rasgos o componentes semánticos.

(3) They converge on a molecular apparatus in the cell nucleus that is often referred to as the cell cycle clock.

En el ejemplo 3 tenemos la unidad léxica (VDE1) molecular apparatus in the cell nucleus y la unidad léxica (VDE2) cell cycle clock, unidas mediante el marcador referred to as.

En VDE1 molecular apparatus in the cell nucleus se hace referencia de manera general al "conjunto de piezas que se valen de moléculas con el fin de actuar en el interior del núcleo celular". En esta descripción encontramos presentes los rasgos: tipo de instrumento [molecular] y ubicación de dicho instrumento [in the cell nucleus].

En VDE2 el conjunto de piezas - apparatus - se sintetiza mediante la presencia de la unidad clock; en este sentido, observamos que VDE2 condensa algunos de los rasgos presentes en VDE1, ya que "aparato" pasa a ser un "instrumento específico - clock" cuya "función" consiste en controlar las fases de la división celular - cell cycle. Por tanto, los rasgos relacionados con el tipo de instrumento y la ubicación de éste desaparecen en VDE2 debido a la condensación que se produce en el contenido semántico.

\begin{tabular}{|l|c|c|}
\cline { 2 - 3 } \multicolumn{1}{c|}{} & $\begin{array}{c}\text { molecular apparatus in the } \\
\text { cell nucleus }\end{array}$ & cell cycle clock \\
\hline Instrumento & + & + \\
\hline Tipo de instrumento & + & - \\
\hline Ubicación & + & - \\
\hline
\end{tabular}

(4) The actual contraction of a myofibril is accomplished by its tiny component units, which are called sarcomeres and are linked end to end to make up a myofibril.

En el ejemplo 4 tenemos la unidad léxica (VDE1) tiny component units y la unidad léxica (VDE2) sarcomeres, unidas mediante el marcador called.

En VDE1 tiny component units se hace referencia de manera general a las "unidades funcionales más pequeñas del músculo". Esta denominación engloba los rasgos relacionados con el "tamaño" y la "utilidad" de este tipo de unidades en el sistema muscular.

En VDE2 sarcomeres se mantienen los rasgos que indican el tamaño de los elementos puesto que esta denominación más específica hace referencia a los elementos más pequeños que forman parte de las miofibrillas. En este caso, observamos que el rasgo de "utilidad" o "funcionalidad" se condensa en VDE2.

\begin{tabular}{|l|c|c|}
\cline { 2 - 3 } \multicolumn{1}{c|}{} & tiny component units & sarcomeres \\
\hline Estructura & + & + \\
\hline Tamaño & + & + \\
\hline Funcionalidad & + & - \\
\hline
\end{tabular}

Tipo 3

Finalmente, se observan casos en que la unidad léxica alternativa activa rasgos diferentes con respecto a la primera unidad que permiten ver el objeto denominado desde diferentes puntos de vista.

Veamos algunos ejemplos:

(5) In theory, gene therapy could also be applied to the reproductive, or germ, cells.

En este ejemplo observamos la VDE1 reproductive cells y la VDE2 germ cells unidas mediante el marcador $o r$. 
Tanto la VDE1 reproductive cells como la VDE2 germ cells hacen referencia a un tipo de células que permiten la creación de nuevos organismos: cuando se juntan células reproductoras de sexos diferentes, dan origen a un nuevo individuo.

Aunque ambos tipos de células hacen referencia a un mismo evento, vemos que en VDE1 reproductive cells, mediante el uso del adjetivo reproductive, se hace énfasis en los rasgos relacionados con el "proceso"; mientras que en VDE2 se hace énfasis en los rasgos que tienen que ver con el "desarrollo", mediante el uso del adjetivo germ.

Así, vemos que ambas variantes coinciden en la función [creación de nuevos organismos], pero difieren en el momento de intervención de cada célula: transcurrida la reproducción [proceso] se origina la germinación [desarrollo].

\begin{tabular}{|l|c|c|}
\cline { 2 - 3 } \multicolumn{1}{c|}{} & reproductive cells & germ cells \\
\hline Función & + & + \\
\hline Fase de intervención & - & - \\
\hline Desarrollo & - & + \\
\hline Proceso & + & - \\
\hline
\end{tabular}

(6) Instead such reasoning appears to follow from the racialized character of much public health research, which at times defaults to reductionist interpretations that emphasize the importance of racial or genetic characteristics.

En el ejemplo 6, la VDE1 racial characteristics y la VDE2 genetic characteristics hacen referencia al conjunto de rasgos de los seres vivos que sirven para distinguirlos de los demás.

No obstante vemos que este conjunto de rasgos se presenta desde diferentes puntos de vista: en VDE1 racial characteristics, el conjunto de rasgos hace énfasis en la clasificación de los seres vivos por su linaje; en VDE2 genetic characteristics, el conjunto de rasgos diferenciales se establece a partir de factores hereditarios.

Vemos que ambas variantes coinciden en su definición de base [conjunto de rasgos diferenciales], pero se distancian debido a que los rasgos diferenciales en VDE1 se establecen desde un punto de vista externo [rasgos físicos, socio-culturales, etc.] y en VDE2 desde un punto de vista interno [caracteres hereditarios, ADN, etc.].

\begin{tabular}{|l|c|c|}
\cline { 2 - 3 } \multicolumn{1}{c|}{} & racial characteristics & genetic characteristics \\
\hline Rasgos diferenciales & + & + \\
\hline $\begin{array}{l}\text { Rasgos diferenciales } \\
\text { externos }\end{array}$ & + & - \\
\hline $\begin{array}{l}\text { Rasgos diferenciales } \\
\text { internos }\end{array}$ & - & + \\
\hline
\end{tabular}

Tal y como acabamos de exponer, la comparación de los componentes semánticos de las VDE unidas por un marcador de variación denominativa explícita (de ahora en adelante MVDE) que explicita la relación entre ellas, nos ha llevado a establecer 3 tipos de relación que mantienen las VDE.

En el siguiente apartado proponemos una denominación para cada tipo de variación, que justificamos con una definición, apoyándonos en los ejemplos anteriormente analizados.

\section{TIPOLOGÍA DE LOS CAMBIOS QUE SE ESTABLECEN ENTRE LAS VARIANTES DENOMINATIVAS EXPLÍCITAS}

En primer lugar, relacionamos cada uno de los tipos anteriormente analizados con una denominación que justificamos y esquematizamos con el fin de dar a entender el cambio que se produce entre los componentes semánticos de cada variante denominativa relacionada explícitamente.

En segundo lugar, explicamos amplia y detalladamente cada uno de los tipos propuestos, estableciendo subtipos en su interior, a partir del análisis del corpus de VDE en el texto.

\section{Expansión}

Corresponde a lo que en este artículo hemos presentado en el tipo 1. Diremos que existe una relación de expansión cuando la segunda variante denominativa explícita (VDE2) añade elementos 
formales y/o de contenido que no están presentes en la primera variante (VDE1). Los ejemplos 1 y 2 anteriormente explicados son casos de expansión.

\begin{tabular}{|l|l|l|} 
VDE1 & md & VDE2 (+) \\
\hline
\end{tabular}

\section{Reducción}

Corresponde a lo que hemos presentado en el tipo 2. Observamos que la reducción se manifiesta cuando los rasgos o componentes formales y de contenido de la primera variante (VDE1) se condensan y sintetizan en la segunda variante (VDE2). Los ejemplos 3 y 4 presentados anteriormente corresponden a la reducción.

\begin{tabular}{|c|c|c|}
\hline $\mathrm{VDE}_{1}$ & $m d$ & $\mathrm{VDE}_{2(-)}$ \\
\hline
\end{tabular}

\section{Refocalización}

Corresponde a la descripción realizada en el tipo 3. Hemos observado que la refocalización se presenta cuando las variantes denominativas (VDE1 y VDE2) coinciden en el plano formal pero no en el plano del contenido. La diferencia entre las variantes en el plano del contenido radica en el énfasis que hace el autor en cada una de ellas. Los ejemplos 5 y 6 anteriormente analizados se agrupan en la refocalización.

\begin{tabular}{|l|l|l|}
$\mathrm{VDE}_{1}$ & $m d$ & $\mathrm{VDE}_{2(\#)}$ \\
\hline
\end{tabular}

A continuación explicaremos cada una de estos tipos de casos de manera detallada.

\subsection{Expansión}

La expansión implica la ampliación de elementos formales y/o de contenido que no están presentes en la primera variante y está vinculada a la explicación porque mediante este proceso se intenta dar a conocer un objeto de manera clara y precisa.

Para Ciapuscio (2003), la expansión se utiliza como mecanismo para resolver dificultades en la comunicación y facilitar la verbalización. En cambio, Gülich \& Kotschi (1995) tratan este mismo tema como resultado del cambio semántico-pragmático que se produce entre dos unidades léxicas unidas por un marcador discursivo.

El MVDE juega también un papel clave en el establecimiento de la relación existente entre las variantes denominativas. Bach (2001) propone una clasificación de marcadores reformulativos que permiten concretar el tipo de relación que se establece entre los enunciados. Así, propone un tipo de marcador de reformulación expansional mediante el cual se amplían algunos o la totalidad de los elementos enunciados del enunciado reformulado ${ }^{\mathrm{vi}}$.

Se observa que las variantes denominativas explícitas que mantienen una relación de expansión podrían situarse en un eje, en el que para algunas se establece una relación de paráfrasis y para otras en cambio, esta relación adquiere casi todos los matices de una definición (paráfrasis definitoria). Este fenómeno lo representamos de la siguiente forma:

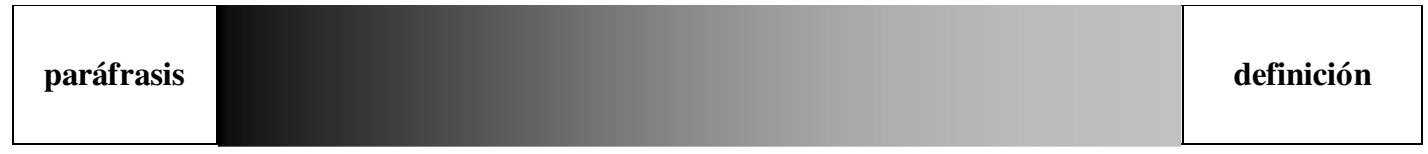

En términos generales, entendemos por paráfrasis la frase que expresa el mismo contenido que otra pero con diferente estructura sintáctica. En este sentido, la paráfrasis está relacionada con la reformulación, tal y como lo afirma Fuchs (1982):

"On a coutume de dire qu'une phrase ou un texte Y constitue une paraphrase d'une autre phrase ou d'un autre texte $\mathrm{X}$ lorsque l'on considère que Y reformule le contenu de $\mathrm{X}$; autrement dit, lorsque $\mathrm{X}$ et $\mathrm{Y}$ peuvent être tenus pour des formulations différentes d'un contenu identique, pour deux manières différentes de «dire la même chose»". (Fuchs 1982: 7).

Al parafrasear el mismo contenido, un emisor siempre corre el riesgo de introducir ciertas diferencias entre $\mathrm{X}$ y su paráfrasis $\mathrm{Y}$, no sólo a nivel de la forma sino también a nivel del contenido, y no sólo a nivel cuantitativo sino también cualitativo.

La reformulación parafrástica Y (en nuestros ejemplos corresponde a VDE2) es cuantitativamente más extensa que $\mathrm{X}$ (en nuestros ejemplos es VDE1) porque en ella podemos apreciar un mayor número de unidades léxicas. Cualitativamente, consideramos que la VDE2 cumple la función de expandir la formulación inicial VDE1 con el fin de hacer un comentario explicativo más claro que contribuye a 
desarrollar el sentido de una frase o expresión de manera más nítida. La paráfrasis, por tanto, hace referencia a una explicación.

En cambio, los casos de definición, aunque consisten también en una reformulación del contenido de una frase o expresión, explican de forma más detallada o desglosada dicho contenido. En este caso, el emisor no se conforma sólo con ampliar la información mediante una paráfrasis explicativa (Fuchs 1994), sino que introduce otros elementos que hacen que la nueva denominación adquiera rasgos aún más específicos.

Estos casos, por tanto, hacen referencia a una explicación que corresponde a una definición lexicográfica. Dichos rasgos específicos aluden a un acto empírico observable que responde a la pregunta explícita o implícita: ¿qué es X? Este cuestionamiento, en palabras de Riegel (1987), corresponde a una pregunta de información sobre el sentido de la unidad codificada X.

Veamos un ejemplo relacionado con la paráfrasis explicativa:

(7) Fortunately, adding a progestin (a synthetic form of the female steroid progesterone) seems to allow men to take a lower androgen dose, an innovation that should eliminate side effects and be safer than taking an androgen alone.

En este ejemplo (7) observamos una expansión tanto desde el punto de vista formal como de contenido. En lo que concierne a la forma, tenemos una unidad progestin $[\mathrm{N}]$, en relación a 7 unidades synthetic form of the female steroid progesterone $[\mathrm{A}+\mathrm{N}+\mathrm{SP}[$ prep. + art. $+\mathrm{A}+\mathrm{A}+\mathrm{N}]]$.

Desde el punto de vista del contenido, vemos que la forma más desarrollada (VDE2) amplía y explicita la información implícita en VDE1 de tal forma que VDE2 adquiere muchos de los matices propios de una definición.

El ejemplo (7) constituye una definición, enunciado definitorio (Riegel 1987) o expansion définitoire (Charolles 1984) porque equivale a una frase metalingüística que J. Rey Debove (1978:163) define como una frase sobre el lenguaje que aparece como tal dentro de su estructura de superficie como consecuencia de los signos que la componen.

Observamos que en (7), la frase metalingüística verbaliza, con la ayuda de los operadores metalingüísticos explícitos (OMEs), los dos tipos de relación que establece Riegel (1987:37): la relación referencial entre un signo y lo que éste designa y la relación semántica entre un signo y su significado.

En los dos tipos de relación, la VDE1 (definendum) está constituida por una denominación que viene marcada generalmente por la anteposición de un artículo indefinido: a progestin (a synthetic form of the female steroid progesterone). En cuanto a la VDE2 (definiens) está constituida generalmente por una secuencia de unidades léxicas precedidas también de un artículo indefinido: a synthetic form of the female steroid progesterone.

En definitiva, y aplicando lo enunciado por Riegel, observamos que la VDE2 synthetic form of the female steroid progesterone (a) constituye una secuencia en uso cuya interpretación se da en función del valor referencial de sus elementos; (b) no reenvía a un objeto particular, sino a una categoría general de objetos; (c) la definición se interpreta como la explicitación de la convención de denominación que asocia la unidad léxica VDE1 a una categoría referencial VDE2.

La VDE2 identifica un contenido particular al que evoca synthetic form of the female steroid progesterone que se interpreta simultáneamente como (a) la explicitación de las propiedades de contenido vinculadas a la unidad codificada (VDE1 progestin); (b) una secuencia más o menos desarrollada de los signos que parafrasean VDE1 de la que ella misma constituye uno de los intérpretes posibles; (c) la verbalización del concepto VDE1 progestin que corresponde al contenido de VDE1.

Cabe resaltar que en nuestro caso tratamos la paráfrasis como un movimiento de expansión que se utiliza en el interior de un texto, con el fin de hacer más accesible el conocimiento o, en otras palabras, para hacer más explícito lo implícito. La paráfrasis que se expresa mediante la forma más desarrollada trata de resaltar algunos, pero no todos, los aspectos más relevantes de la unidad léxica menos desarrollada. En síntesis, una VDE1 puede ser interpretada por una secuencia parafrástica VDE2 (definición) que funciona como la forma desarrollada de su contenido.

En nuestro corpus de análisis (301 ocurrencias de VDE) hemos encontrado 40 ocurrencias que corresponden a paráfrasis explicativas (72\%) y 15 ocurrencias que corresponden a definiciones (28\%). Los MVDE que contribuyen a establecer una relación de paráfrasis explicativa son los siguientes en su respectivo orden de aparición: parenthesis (35\%), or (21\%), known as (14\%), named (7\%), termed (7\%), viewed $(7 \%)$, called $(5 \%)$ y referred to as $(4 \%)$.

Los MVDE que establecen relación de definición son: parenthesis $(69 \%)$, or (19\%), called (6\%) y that is $(6 \%)$. Se observa que el parenthesis y el marcador or son los marcadores más utilizados para establecer ambos tipos de relación.

Los resultados dan pie para pensar que la información parentética contribuye bastante al desarrollo de los aspectos explícitos del discurso, de tal forma que el destinatario pueda interpretar de manera adecuada el mensaje y, por consiguiente, pueda lograr una apropiada representación conceptual del tema 
o dominio en general. Vemos también que el marcador or permite marcar un momento particular del discurso en el que de manera inesperada se añade un nuevo elemento de reflexión, un nuevo razonamiento de índole distinta a los presentados anteriormente.

"Tras enunciar A, hago una pausa para añadir "or B", esto es, como continuación de A, añado un nuevo argumento inesperado (B)" (Tricás 1995:102).

Dentro de los materiales del tipo 1 que hemos denominado expansión, el análisis de los casos que cumplen estas condiciones nos ha permitido observar que existen subtipos y procedimientos distintos para expresar esta relación de expansión.

\subsubsection{Expansión metafórica}

En la expansión metafórica, la unidad léxica desarrollada no sólo cumple la función de aclarar y precisar una realidad o concepto, sino que guarda cierta relación de semejanza con la otra variante. A esta relación de semejanza se le conoce con el nombre de metáfora.

Desde el punto de vista filosófico ${ }^{\text {vii }}$ la metáfora es más que un recurso retórico. Para Aristóteles es una «trasposición» del significado de una cosa a otra, que no debe entenderse como su simple cambio de nombre (metonimia: «toga», por abogacía). No es un simple cambio de significante, sino la integración, o transporte, en el significado de un término, de una parte del significado de otro por medio de una imagen.

Según J.A. Richardson, mediante una sola palabra la metáfora mantiene activos dos pensamientos distintos, lo que permite a Paul Ricoeur afirmar, en el contexto de su teoría hermenéutica, que la metáfora es un enunciado que, en el marco de un discurso, y mediante una predicación no pertinente, apela a una nueva pertinencia fundada sobre la semejanza y engendra una redescripción heurística de la realidad. Por ello, Ricoeur interpreta el significado metafórico como un aumento cognitivo obtenido por la identidad de significados con permanencia de la diferencia (identidad de la diferencia).

R. Jakobson también considera la metáfora como la similitud de un referente que figura en la realidad descrita por otro referente, mediante cuyo nombre se le designa. Por su parte, H.G. Gadamer cree que la metáfora es expresión de una facultad fundamental del lenguaje, la capacidad metafórica, que es una forma propia, lógica y lingüística, de construcción de conceptos.

Para Lakoff \& Johnson (1991), la metáfora impregna la vida cotidiana, no solamente el lenguaje, sino también el pensamiento y la acción. Según estos autores, "nuestro sistema conceptual ordinario es fundamentalmente de naturaleza metafórica".

Basados en las definiciones antes mencionadas, destacamos los siguientes aspectos por ser útiles para la explicación de la expansión a manera de explicación metafórica.

En primer lugar, la idea de semejanza; es decir, la posibilidad de expresar el contenido de un término (VDE1) por el contenido de otro con el que guarda cierta similitud (VDE2).

En segundo lugar, la idea de comparación con un objeto cotidiano que forma parte de nuestra experiencia diaria.

En tercer o último lugar, la idea de simplificar contenidos abstractos mediante el uso de objetos que aluden a contenidos menos abstractos y, por ende, más concretos.

"Si el significado de la forma A afecta el significado de la forma B, entonces, cuanto más próxima está la forma A a la forma B, el efecto del significado de A sobre el significado de B será más fuerte." (Lakoff et al., 1991:170)

Así, por ejemplo:

(8) Genes give rise to proteins (the main workers of cells), and defective genes can yield disease when they cause cells to make the wrong amount of a protein or an aberrant form of it.

En este caso, desde una perspectiva formal, tenemos que la VDE1 tiene una unidad proteins [N], en relación a la VDE2 que tiene 4 unidades main workers of cells $[\mathrm{A}+\mathrm{N}+$ prep. $+\mathrm{N}]$.

Desde el punto de vista del contenido, constatamos que la VDE1 proteins tiene sus orígenes del griego proteiôn que significa preeminente — más importante que otros- - Si ahondamos en el contenido de la VDE1, encontramos que las proteínas están asociadas directamente a los genes [genes give rise to proteins] y que del volumen o la cantidad de éstas depende en gran parte el funcionamiento del organismo [...cause cells to make the wrong amount of a protein], ya que las proteínas "son sustancias muy versátiles que cumplen diferentes funciones: catalizadoras, reguladoras, transportadoras de oxígeno, almacenadoras, defensivas, energéticas, entre otras". En la VDE2 encontramos cada uno de estos rasgos mediante la utilización de la explicación metafórica main workers of cells.

La VDE2 establece una relación de semejanza con la VDE1 mediante el uso de la expresión main workers que realza, en primer lugar, el importante papel de las proteínas y la función que cumplen. La unidad léxica work(er) forma metáforas que tienen implícita la idea de esfuerzo/actividad (e.g. costar trabajo = esforzarse). 
Así, una unidad léxica abstracta como proteins se puede llegar a expresar de una manera más concreta y transparente o, en palabras de Lakoff \& Johnson (1991), en términos más humanos; es decir, de una forma que tiene sentido para la mayoría de la gente.

En toda organización, existen jerarquías que hacen que algunos trabajadores estén por encima de otros; en este sentido, la explicación metafórica de las proteínas [main workers of cells] nos hace comprender que éstas también están estructuradas jerárquicamente y que dentro de su jerarquía, son ellas las que actúan por encima de otras sustancias.

En síntesis y teniendo en cuenta los planteamientos de Ciapuscio (2003), la expansión a manera de explicación metafórica se utiliza con el fin de (a) asegurar la comprensión del destinatario. En otras palabras, el autor intenta dar la información más cercana a su experiencia diaria mediante el uso de objetos típicos de su vida cotidiana. (b) estructurar lo menos concreto en términos más concretos que estén relacionados directamente con nuestra experiencia. (c) procurar que el conocimiento especializado sea más cercano a la experiencia del destinatario.

\subsubsection{Expansión no metafórica}

Se trata de una expansión explicativa en la que la variante expandida no establece una relación metafórica con la otra variante. En este caso, un mismo concepto se expresa mediante formas diferentes y una de dichas formas intenta expresar de manera más explícita una misma realidad.

En este subtipo de expansión, observamos claramente un movimiento de opacidad-transparencia. Si entendemos la opacidad como el fenómeno que impide el paso de la luz e impide ver a través de su masa lo que hay detrás, y la transparencia como el fenómeno contrario al de la opacidad, que permite ver la realidad de los hechos sin ocultar o silenciar, diremos, entonces, que el movimiento de opacidadtransparencia se manifiesta en el discurso cuando pasamos de lo "(-) conocido" a lo "(+) conocido" o mejor aún de lo "implícito" a lo "explícito".

A través de este movimiento de opacidad-transparencia, el autor intenta optimizar el discurso y beneficiar al destinatario de tal forma que éste tenga la posibilidad de saber todo o casi todo a cerca del enunciado en cuestión. En este sentido, podemos afirmar que en este movimiento intervienen, el emisor quien se sitúa al lado del "saber-experto" y el destinatario quien se sitúa al lado del "saber-no experto", por cuanto requiere de una explicación para acceder al conocimiento.

Los subtipos de expansión constituyen un tipo de variación denominativa explícita que tiene que ver con los procedimientos de reformulación parafrástica y más específicamente con lo que Gülich \& Kotschi (1995) y Ciapuscio (2003) han denominado procedimientos de ilustración, o con lo que Kleiber (1984) denomina relación de designación.

"Illustration procedures are a resource experts frequently select to present knowledge by making it accessible to a (semi)lay interlocutor" (Ciapuscio 2003:216)

En palabras de Ciapuscio, estos procedimientos se ponen en práctica cuando surge una "fuente de conflicto" (VDE1) que requiere ser resuelta con el fin de lograr la progresión textual (VDE2).

El siguiente ejemplo ilustra este fenómeno:

(9) If certain of these antioxidants were unique to sperm or to seminal fluid, investigators would be able to design drugs that in - activated those particular enzymes but did not deprive other cells of antioxidant defenses.

Desde el punto de vista de la forma vemos que la VDE1 tiene una unidad (sperm) [N], mientras que la VDE2 tiene dos unidades (seminal fluid) [adj. + N].

En el plano del contenido la VDE1 sperm hace énfasis en la "célula que se produce en el órgano masculino y que puede entrar y fecundar el órgano femenino". Es decir, que implícitamente esta denominación encierra los rasgos de célula, propio del órgano masculino y fecundación [semilla].

La VDE2 seminal fluid incluye cada uno de los rasgos anteriores mediante el uso del adjetivo seminal y hace explícito el rasgo de líquido mediante el uso de fluid. Esta expansión, permite al autor o productor del texto presentar un rasgo o componente al destinatario con el que se materializa el objeto en cuestión [líquido].

Según Gülich \& Kotschi (1995), los procedimientos de expansión parafrástica son "schemata" regulares del comportamiento lingüístico por medio de los cuales los destinatarios aseguran la comprensión mutua.

En este ejemplo, el autor decide utilizar la unidad léxica, sperm, en lugar de utilizar una forma más transparente y común, semen. No obstante, el autor decide introducir VDE2 seminal fluid que, no sólo explicita algunos de los rasgos implícitos de VDE1, sino que permite al destinatario "menos especializado" acceder de una manera más fácil al conocimiento.

"Si le texte est concis, l'expression équivoque, la pensée obscure, on sent l'utilité de la paraphrase qui, par une habile et sage amplification, dégage le sens et le rend facilement saisissable à l'esprit" (Fuchs 1994:15) 
En síntesis, vemos que un autor decide explicitar una VDE (a) para evitar problemas de comunicación durante la interacción; (b) para comunicar al destinatario un determinado conocimiento especializado de manera efectiva y accesible; (c) para verbalizar contenidos complejos y abstractos de manera simplificada.

De esta última justificación (c), se desprende la idea de concreción discursiva que consiste en renombrar información abstracta de forma no abstracta (Ciapuscio 2003).

Tal es el caso que se presenta cuando un autor introduce una sigla por primera vez en el discurso, e inmediatamente introduce una explicación que permite precisarla con el fin de que ésta no se perciba como aislada o separada de la realidad. Por ejemplo:

(10) Today scientists know that deletions in any of three specific regions on the $\mathrm{Y}$ can cause infertility, and they have learned that each of these regions referred to as AZF (for azoospermia factor) a, b and c - contains multiple genes.

El análisis realizado sobre los subtipos de expansión arroja los siguientes resultados cuantitativos: el total de ocurrencias de expansiones por explicación metafórica en nuestro corpus de análisis es de 8 (corresponde al 17\% del total de casos de variación) y el total de ocurrencias de expansiones por explicación no metafórica es de 47 (83\% del total de casos de variación).

Estos resultados dan pie para pensar que desde la perspectiva de la producción discursiva, los autores utilizan menos el recurso de la metáfora para simplificar o hacer más comprensible el conocimiento especializado. Lo anterior se debe quizás al hecho que la expresión de conceptos en términos metafóricos es menos usual en la producción por parte de los especialistas. Estos datos también nos permiten deducir que el especialista intenta evitar el uso del recurso metafórico para proteger la rigurosidad y objetividad de su discurso científico.

Los subtipos de expansión tratados como expansión metafórica se expresan en todos los casos mediante una paráfrasis explicativa y los MVDE utilizados son el parenthesis (56\%), seguido de or $(28 \%)$, termed $(8 \%)$ y viewed as $(8 \%)$.

Los subtipos de expansión denominados expansión no metafórica se expresan tanto por paráfrasis explicativas como por definiciones y los MVDE utilizados para introducir dicho subtipo de expansión son: parenthesis (52\%), or (20\%), known as (13\%), called (7\%), y en menor escala con un (2\%), referred to as, termed, that is, y viewed as.

\subsection{Reducción}

La reducción corresponde a la descripción realizada en el tipo 2 y representa un tipo de variación contrario al de la expansión, debido a que los rasgos o componentes formales y de contenido de la primera variante $(V D E 1)$ se condensan y sintetizan en la segunda variante (VDE2).

En efecto, la reducción está vinculada a la condensación, es decir, a la supresión de la extensión de un discurso a sus puntos esenciales. La reducción se materializa en el interior del discurso de diferentes maneras: reduciendo el tamaño, la cantidad o la intensidad.

La reducción del tamaño se materializa ante todo por la supresión del número de unidades; en nuestro trabajo, estas unidades equivalen al número de tokens presentes entre la VDE1 y la VDE2. Por ejemplo:

(11) When we find a clear overlap, we piece together the overlapping partial sequences into ever lengthening segments called contigs.

En este caso tenemos, desde el punto de vista formal, 3 unidades (VDE1) ever lengthening segments $[\mathrm{A}+\mathrm{A}+\mathrm{N}]$ en relación a una sola unidad (VDE2) contigs $[\mathrm{N}]$.

La reducción de la cantidad trae consigo la supresión de un contenido ponderativo o intensificador; en nuestro caso, dicha reducción del tamaño está vinculada a la condensación semántica que experimenta la variante reducida (VDE2). Por ejemplo:

(12) Neurons within the cell group are rich in receptors for sex hormones, both for androgens-testosterone is the main representative-and for female hormones known as estrogens.

En VDE1 se hace referencia de manera general a la "sustancia segregada por determinados órganos, que regula la actividad de otros órganos [hormones], específicamente en el sexo femenino [female]."

En VDE2 estrogens, los rasgos que hacen referencia a la "sustancia", "órganos" y al "tipo de sexo" quedan implícitos, ya que la unidad léxica estrogens hace referencia de manera específica a las "hormonas sexuales femeninas que intervienen en la formación y desarrollo de los órganos sexuales". En este sentido, observamos que los órganos mencionados en VDE1 de manera general se condensan en VDE2 como órganos sexuales.

Por último, la reducción de la intensidad o supresión del grado de fuerza con que se manifiesta un fenómeno se materializa mediante el uso del MVDE que une las dos VDE. Así, por ejemplo: 
(13) But by the time symptoms occur-usually pain or bleeding from an organ or a noticeable mass or lump - many tumors have already grown quite large.

En este ejemplo, el marcador or establece una relación de disyunción entre las dos variantes, que puede ser interpretada como incluyente (equivalencia) o excluyente (no equivalencia). Según Cortés y Martínez (1996), la lógica prefiere el uso de la disyunción en sentido inclusivo, mientras que el lenguaje ordinario recurre con mayor frecuencia a «or» excluyente. En nuestra opinión, en los casos en que or actúa como marcador los dos valores permanecen subyacentes en su uso, y sólo el contexto discursivo aclara cuál de los dos se activa con más fuerza ${ }^{\text {viii }}$.

La reducción además está directamente relacionada con el implícito y, por tanto, ocasiona un movimiento opuesto al de la expansión porque opera en una dirección contraria: de lo explícito a lo implícito; o en otras palabras de lo (+) conocido a lo (-) conocido, o de un conocimiento (-) especializado a un conocimiento $(+)$ especializado.

Gülich \& Kotschi (1995) consideran la reducción como la "condensación semántica" que se presenta entre la "expresión de referencia" y la "expresión de tratamiento".

Ciapuscio (1993), por su parte, establece dos tipos de reducción — supresión y condensación—no a nivel de las unidades, sino a nivel de la información textual; esto es, la reducción o supresión de la información en el paso de un texto especializado a un texto de divulgación científica.

La reducción por supresión, en términos de Ciapuscio, hace referencia a la omisión de información que por diversos motivos no es relevante o conveniente en la versión divulgada. La reducción por condensación se presenta cuando los contenidos que ocupan una gran extensión en los textos fuente se condensan y sintetizan en el texto de divulgación.

Adelstein et al., (2000) trabajan la temática de la reducción desde el punto de vista formal; en esta propuesta, un sintagma terminológico pleno ${ }^{\mathrm{ix}}$ sufre una alteración de la secuencia lineal mediante la elisión de uno o más constituyentes.

De acuerdo con la propuesta de Bach (2001), mediante el uso de marcadores reductivos se suprimen algunos o la totalidad de los elementos enunciativos que, en nuestro caso, es objeto de la variación (VDE2).

En este tipo de variación consideramos importante trabajar la idea de reducción planteada por Gülich \& Kotschi y tener en cuenta algunos de los elementos formales determinados por Adelstein et al. También consideramos pertinente observar cuáles de los marcadores seleccionados introducen este tipo de cambio.

A nuestro modo de ver, la condensación semántica responde a la síntesis discursiva que explora un determinado sentido dentro de la gama de posibilidades de su trasfondo sémico. Es en este nivel donde el autor adopta el silencio y da prelación a lo implícito.

Este tipo de caso de variación tiene relación con el acto o proceso de denominación propuesto por Kleiber (1984, 1990). En este sentido, decimos que la VDE1 establece una asociación referencial con la VDE2. Esta asociación tiende a ser duradera porque no tiene como objetivo una designación momentánea y transitoria; sino que por el contrario, permite la fijación de una regla referencial estable que posibilita la utilización de la denominación (VDE1) por el objeto denominado (VDE2).

Una vez establecida dicha asociación, observamos que el paso de una paráfrasis o definición o "denominación lexical/item lexical" (Kleiber 1990) a una unidad léxica condensada requiere de un "conocimiento referencial" avanzado.

"On ne peut pas utiliser un nom de manière significative pour référer à quelqu'un ou quelque chose, à moins de savoir à qui ou à quoi l'on se réfère par le moyen de ce nom. Autrement dit, il faut être prêt à substituer une description au nom". (Strawson 1973:203)x.

Así pues, este tipo de caso de variación muestra, a nuestro modo de ver, el conocimiento especializado que posee el autor, el cual no sólo posee la autoridad sino la competencia cognitiva para llevar a cabo este proceso. Este mismo proceso de denominación es equiparable con lo que denominaremos en este artículo, procedimiento de terminologización. Es decir, el procedimiento que siguen los especialistas para introducir la Unidad Terminológica (UT); o bien, cuando pasan de la "forma desarrollada" a la "forma condensada o reducida".

Dentro de los materiales del tipo denominado reducción, el análisis de los tipos de casos que cumplen estas condiciones nos ha permitido ver que existen subtipos y procedimientos distintos para expresar la relación de reducción.

\subsubsection{Reducción por elisión}

La reducción por elisión es una reducción elíptica por concentración semántica que forma parte de la reducción léxica (Adelstein et al. 2000 y Adelstein 1998), un procedimiento que permite la formación de otra unidad que funciona como variante de un sintagma terminológico pleno

Según Adelstein (1998), la reducción por elisión presenta las siguientes características: 
a) En el plano textual este tipo de reducción contribuye a la cohesión y coherencia textuales, puesto que favorece la economía verbal.

b) En el plano conceptual, el sintagma terminológico reducido absorbe los valores conceptuales o de contenido de los constituyentes elididos.

c) En el plano léxico, este tipo de reducción da origen a variantes terminológicas lexicalizables, que tienen el mismo significado o contenido que el sintagma terminológico pleno, pero no la misma forma. En este sentido, el sintagma terminológico reducido puede ocurrir en el interior del texto aún en ausencia del sintagma terminológico pleno.

d) En el plano sintáctico, el sintagma terminológico reducido, por formar parte de una variante denominativa, debe mantener la categoría gramatical del sintagma terminológico pleno.

Podemos decir que estamos sólo parcialmente de acuerdo con estos planteamientos, dadas las características de nuestro corpus y los casos que hemos detectado como reducciones elididas:

En primer lugar, en el plano conceptual o de contenido, nuestros tipos de elisión dan pie para pensar que el sintagma terminológico reducido absorbe "algunos" pero no todos los valores conceptuales de los constituyentes elididos. En segundo lugar, en el plano léxico, nuestros ejemplos nos hacen pensar que las variantes terminológicas no sólo varían en su forma, sino que dicho cambio formal trae consigo un cambio en el contenido ${ }^{\mathrm{xi}}$.

Desde una perspectiva pragmático-discursiva la reducción por elisión permite al especialista pasar de un conocimiento "aparentemente" más general, a un conocimiento más abstracto o especializado.

El procedimiento de terminologización se produce cuando el autor, haciendo uso del recurso morfoléxico (tomar dos constituyentes del sintagma terminológico pleno), forma una unidad terminológica monoléxica que intenta condensar el contenido del sintagma terminológico pleno. En este caso, observamos un movimiento contrario al de la expansión: transparencia-opacidad por cuanto estamos tratando con un proceso inverso: de lo explícito a lo implícito.

En el movimiento de transparencia-opacidad, el autor o especialista muestra poca consideración por el destinatario — no especialista — al suministrar denominaciones "más técnicas" y, por tanto, más opacas u oscuras para su comprensión.

En este sentido, el autor parte del supuesto que sus destinatarios poseen un conocimiento especializado y, por tanto, introduce un tipo de cambio (reducción) que le permite utilizar las unidades léxicas especializadas propias del dominio en cuestión. Así, ambos, emisor y destinatario, se sitúan al lado del "saber", o en otras palabras, el autor espera que su destinatario trate de estar a la misma altura de su competencia cognitiva.

El siguiente ejemplo ilustra este fenómeno:

(14) As Blackmore notes, genes can also be transformed by spontaneous changes called mutations.

En este ejemplo, en el plano de la forma tenemos dos unidades spantaneous changes $[\mathrm{A}+\mathrm{N}]$ en relación a una sola unidad mutations $[\mathrm{N}]$. En este caso, la reducción no es el resultado de la elisión de uno de los componentes del sintagma terminológico pleno a nivel formal, pero sí la elisión de algunos rasgos o componentes del contenido del sintagma terminológico pleno.

En el plano del contenido, la VDE1, spontaneous changes, hace referencia a la "alteración de los genes que se produce de forma natural". La VDE2, mutations, hace referencia a la "alteración que ocurre en el interior de los genes, específicamente en el funcionamiento normal de la proteína expresada". Como podemos observar, en VDE2 se conservan los rasgos de "alteración" y el objeto que padece dicha alteración: los genes; no obstante, notamos que se reducen los rasgos o componentes que tiene que ver con la manera como se producen dichos cambios o alteraciones (natural-espontánea).

En este caso, se elide la carga semántica que tiene el [A] de la VDE1 spontaneous; aunque este [A] conduce a un cambio en el contenido, no es determinante para especificar el concepto, ni ubicarlo dentro de la estructura conceptual del dominio en cuestión.

De este ejemplo deducimos que la reducción por elisión se manifiesta en nuestro corpus bien sea porque se eliden algunos de los componentes del sintagma terminológico pleno (plano de la forma) y se utilizan recursos morfoléxicos para formar la unidad terminológica monoléxica, o bien porque se eliden los componentes del sintagma terminológico pleno a nivel conceptual (plano del contenido) y, por tanto, no se recurre a ninguna estrategia de formación de palabras, para introducir la unidad terminológica monoléxica. Cabe resaltar que ambas formas de elisión afectan siempre el plano del contenido.

En este caso, el procedimiento de terminologización se produce cuando el autor, haciendo uso de su competencia cognitiva, introduce una unidad terminológica monoléxica propia del dominio. En cuanto al movimiento de transparencia-opacidad, observamos que el autor pasa de una unidad terminológica más desarrollada y, por tanto más explicativa, a una unidad terminológica de carácter más técnica o especializada. 
En síntesis, un autor decide condensar una VDE (a) para otorgar al texto un mayor nivel de especialidad, mediante la inserción de unidades propias del dominio; (b) para comunicar al destinatario un conocimiento especializado de una manera especializada; (c) para verbalizar contenidos simples de manera compleja y abstracta.

\subsubsection{Reducción por abreviación}

En la reducción por abreviación, la unidad léxica más desarrollada se comprime en una sigla. Nenadić et al. (2002:2155-2162) hacen una propuesta que tiene que ver con el manejo de los términos y sus variantes recuperados de manera automática a partir de los textos especializados.

En dicha propuesta, el reconocimiento de la variación se incorpora en el proceso de recuperación automática de los términos y, para ello, se tiene en cuenta la variación de los términos a nivel pragmático, léxico-semántico, sintáctico, morfológico y ortográfico. Desde esta perspectiva, los autores en mención proponen la siguiente clasificación para el tratamiento de las siglas:

a) Formas combinadas: en general las siglas se forman a partir de la selección de las primeras letras o de las sílabas de una expresión desarrollada o expandida. Se trata de prefijos e infijos, e.g. acetyl, trans, hydro, etc., que se utilizan regularmente en los patrones de formación de términos (e.g. chloramphenicol acetyl transferase (CAT) ).

b) Inserción: se trata de una palabra que está presente en la forma expandida pero que no aparece en la formación de la sigla (e.g. thyroid hormone receptor (TR)).

c) Omisión: en este caso, una palabra que no está presente en la forma expandida, sí aparece en la formación de la sigla (e.g. [human] estrogen receptor (hER)).

d) Sigla plural: se trata de una sigla en la que está presente el plural de la forma expandida (e.g. retinoid $X$ receptors (RXRs)).

e) Sigla recursiva: en este caso, la forma expandida de una sigla contiene una abreviación (e.g. $C$ REB-binding protein (CBP)).

f) Sigla coordinada: en este caso, las siglas están presentes en el interior de una estructura coordinada (e.g. estrogen (ER) and progesterone (PR) receptors).

g) Sigla parcial: en este caso, la sigla contiene una parte de su forma expandida, usualmente se trata de palabras griegas o latinas (e.g. retinoid $X$ receptor alpha (RXR alpha)).

h) Sigla fórmula: en este caso, la sigla contiene (una parte de) una fórmula química (e.g. lalpha, 25-dihydroxyvitamin D3 [1,25 (OH) 2D3]).

Esta clasificación de Nenadić et al., nos servirá como base para describir la forma como se manifiesta en nuestro corpus el subtipo de variación que reduce sus sintagmas plenos a una forma abreviada.

Veamos el siguiente ejemplo:

(15) Pero no resulta fácil manipular el ARNm. De ahí que no trabajemos con éste, sino con copias estables de ADN obtenidas a partir de dichos ARNm. Estas copias se denominan $A D N$ complementario $(A D N c)$ de las moléculas de ARNm.

La reducción que se presenta en este ejemplo corresponde, según la clasificación presentada (Nenadić et al.) a una sigla recursiva, es decir que la forma expandida contiene otra sigla, en este caso $A D N$.

En este ejemplo, desde el punto de vista de la forma tenemos dos unidades ADN complementario $[\mathrm{N}+\mathrm{A}]$ en relación a una unidad $A D N c$.

Desde el punto de vista del contenido observamos que la denominación ADN complementario, hace referencia a un ADN que ha sido copiado de una plantilla de ARN. En este sentido, esta variante puede hacer referencia a un ADN complementario o a un ADN copia. Esta dos denominaciones pueden reducirse en una misma sigla, la cual por su condición abreviada conserva los mismos rasgos pero de forma menos específica, ya que sin la forma expandida sería difícil intuir la característica de copiado.

Los datos analizados arrojan los siguientes resultados: en nuestro corpus hemos encontrado un total de 184 ocurrencias que corresponden al tipo reducción (61\% del total de casos de variación), de los cuales $122(66 \%)$ son reducciones por elisión y 62 (34\%) son reducciones por abreviación.

La reducción por elisión se materializa en el corpus acompañada de los siguientes MVDE: called $(46 \%)$, or (18\%), known as (16\%), parenthesis (13\%), termed (3\%), refer y named (2\%). Los MVDE que introducen la reducción por abreviación son: parenthesis $(66 \%)$, or $(14 \%)$, known as $(10 \%)$, called $(10 \%)$. Estos datos dan pie para inferir que los MVDE que podemos situar entre los más productivos para introducir la reducción son: called y parenthesis, lo que equivale a decir que, ambos marcadores contribuyen en la realización de un acto de denominación o de terminologización. 


\subsection{Refocalización}

Llamaremos refocalización a las variantes denominativas (VDE1 y VDE2) que coinciden en el plano formal pero no en el plano del contenido. La diferencia entre las variantes en el plano del contenido radica en el énfasis que hace el autor en cada una de ellas y en su capacidad para observar un mismo objeto desde diferentes puntos de vista. Esto es, el autor presenta dos formas (VDE) en las que focaliza la unidad léxica de manera distinta.

Para comprender mejor este fenómeno, podemos imaginar el rodaje de una película, en la que el director del rodaje es el autor del texto: El autor presenta un objeto (Unidad Léxica). El foco ilumina ciertos aspectos de la unidad léxica, que aparecen visibles "en escena", (componentes del contenido expresados por la VDE1). Cuando el autor mueve el foco, a través del MVDE, se presenta el objeto en escena priorizando otra perspectiva (VDE2). Así, algunos de los rasgos de la unidad léxica se mantienen inalterables, otros no se ven y otros quedan iluminados (componentes del contenido comunes y diferenciales). De este modo, el autor da relevancia a otros aspectos de la unidad léxica objeto de la variación. Este movimiento del foco conduce, a su vez, que otros rasgos queden en la oscuridad.

Esta explicación permite relacionar la refocalización con la naturaleza poliédrica que presentan las unidades terminológicas. Las unidades terminológicas (UT) se han contemplado como unidades poliédricas en el marco de la Teoría Comunicativa de la Terminología (TCT) y se afirma que pueden ser vistas al mismo tiempo como unidades lingǘsticas, cognitivas y socioculturales y además como unidades multidimensionales conceptual y formalmente (Cabré 1999:70).

En este trabajo tomamos el tema de la poliedricidad en la perspectiva más específica y lo tratamos como la posibilidad de observar una UT desde diferentes perspectivas en lo que concierne al plano del contenido; esto es, el autor tiene la opción de presentar las VDE en función de la cara del poliedro con que decida observar cada variante.

Condamines et al. (1997) al plantear el tema de la polisemia en el discurso especializado, hacen uso del concepto de punto de vista con el fin de comprobar las diferencias entre el discurso general y el discurso especializado. Esta noción de punto de vista permite a las autoras establecer un método que pone en evidencia tanto los casos de poliacepciones como la existencia de puntos de vista colectivos.

El estudio realizado por Condamines et al. muestra cómo a través de la noción de puntos de vista se puede dar explicación de la sinonimia y la polisemia, fenómenos considerados polémicos en el discurso especializado.

"La notion de point de vue peut être associéè à un choix individuel (le même que l'on trouve dans toute actualisation de langue en discours) ou à un choix collectif, celui qui fait qu'un ensemble de locuteurs découpent le monde de la même manière, celle qui correspond au domaine dans lequel ils évoluent". (Condamines et al. 1997:183).

En nuestro caso, consideramos pertinente tratar el tema de la variación denominativa y más específicamente el tipo de caso denominado refocalización, haciendo uso del concepto de punto de vista. Este concepto junto al concepto de poliedricidad permiten dar cuenta de la existencia de perspectivas diferentes cuando se observa una misma realidad u objeto.

El análisis de los tipos de casos denominados refocalización nos ha permitido observar que existen subtipos y procedimientos distintos para expresar este tipo de relación.

\subsubsection{Refocalización externa}

En este tipo de refocalización las variantes denominativas difieren en su contenido, porque el emisor, valiéndose de un conocimiento específico, visualiza dichas variantes desde puntos de vista diferentes. En la refocalización externa entra en juego la creatividad léxica planteada por Mortureux (1984), que se caracteriza por la prioridad dada al objeto designado: el nombre puede, por diferentes medios, tender a una cierta descripción del objeto que designa. Para Mortureux, las denominaciones presentan características variadas desde el punto de vista de los nombres producidos y de su funcionamiento semántico y pragmático.

Estas afirmaciones sobre la creatividad léxica concuerdan con lo que proponemos como refocalización externa, porque pensamos que el autor presenta el mismo objeto desde puntos de vista diferentes motivado por los caracteres variados de las denominaciones producidas.

"Il s'en suivra que le rapport entre le concept et le signifié comporte toujours une part de motivation qui suscite et oriente les choix de dénomination. Le signe linguistique ainsi produit ne peut être totalement arbitraire de ce point de vue. Même lorsque le concept est nouveau, le choix de son expression verbale, est motivé et conditionne indirectement la formation du signifiant". (Diki-kidiri et al, en prensa).

La presentación de las variantes desde puntos de vista diferentes o desde distintas caras del poliedro, nos da pie para pensar que el autor utiliza una estrategia discursiva a través de la cual muestra expresiones que pertenecen a un grupo social determinado. 
"La sélection d'un angle de vue, c'est-à-dire d'une perception, d'un signifié est tributaire d'habitudes, d'analogies, de stratégies d'appréhension qui sont largement conditionnées par la conscience de l'expérience antérieure dont on peut retrouver les traces dans la mémoire des mots". (Diki-kidiri et al, en prensa).

Somos conscientes que cada grupo o individuo que pertenece a una comunidad científica maneja unas estrategias discursivas y de redacción que le son muy propias. Tal y como señalan Diki-kidiri et al., (en prensa), el ser humano acumula durante su vida una cantidad inconmensurable de experiencias que constituyen su base de conocimientos y su memoria. Estas experiencias se arraigan en lo más profundo del ser consciente, subconsciente o inconsciente.

No obstante, el ser humano, además de su consciente individual, opera como ser humano colectivo; es decir que al estar inmerso en una comunidad, se ve obligado a adaptarse a ella mediante el uso de ciertas estrategias.

En este sentido, según Diki-kidiri et al., cada individuo pertenece a varias comunidades humanas, sin ninguna limitación. Una comunidad humana no es homogénea, especialmente cuando dicha comunidad es amplia, porque engloba una gran cantidad de micro-comunidades, capas sociales, diversos niveles, enclaves, particularidades. El flujo de información en el seno de una comunidad estará influenciado necesariamente por esta multilateralidad intrínseca de la comunidad como entidad social.

Una comunidad existe porque sus miembros son conscientes de ello y la reivindican. La construcción de los símbolos y valores de referencia compartidos por la comunidad facilita la comunicación entre los miembros de ésta. Esto puede aplicarse tanto para una vieja pareja que comparte la vida durante mucho tiempo, como para un equipo de investigadores que trabajan juntos durante mucho tiempo analizando el mismo objeto. En ambos casos, los miembros de esta micro-comunidad han aprendido a conocerse, a acumular las mismas experiencias de la vida diaria, del trabajo, etc.

Ambos casos aluden a la memoria colectiva de lo que constituye su pasado común, su deontología, los valores que los unen, la manera de expresarse y de comunicarse entre ellos. La memoria colectiva juega un papel importante cuando una comunidad determinada intenta describir por primera vez una realidad. Dicha realidad puede corresponder a un objeto, una tecnología, un descubrimiento entre otros y su descripción puede provenir del interior o exterior.

La realidad que proviene del exterior ha sido previamente conceptualizada y adaptada por otra comunidad. Desde este punto de vista, esta "nueva" realidad se compara con las realidades existentes, con el fin de otorgarles una categoría y una denominación, de modo que el individuo pueda integrarlas en su base de conocimientos como un objeto conocido. La conceptualización y adaptación dependen en gran parte de la distancia cultural existente entre ambas comunidades.

Un ejemplo de ello lo constituyen las nuevas tecnologías en todos los ámbitos (medicina, ingeniería, informática, etc.) que inundan los mercados en diferentes comunidades y culturas y que, en algunos casos, provienen de culturas bastante alejadas unas de las otras. Estas nuevas tecnologías se difunden y se aceptan en función de la aportación que ellas hacen a la comunidad. En este sentido, la denominación de dicha tecnología se adecuará al nuevo entorno o se conservará tal cual, de modo que logre expandirse fácil y rápidamente.

"Il faut souligner aussi que plus la distance culturelle entre la communauté d'origine de la nouveauté et la communauté réceptrice est grande, plus grande est l'onde de choc culturel qui accompagne l'appropriation de la nouveauté.". (Diki-kidiri et al, en prensa)

La realidad que proviene del interior de la misma comunidad, toma generalmente como fuente una parte muy pequeña de la comunidad, bien sea una sola persona (inventor) o una micro-comunidad (sociedad, compañía, equipo de investigadores, etc) y toda la problemática se resume en observar la manera como esta realidad se difunde en el seno de la comunidad y se convierte en un objeto común para todos.

A manera de ejemplo podemos citar los nombres científicos y comerciales de ciertos medicamentos. El nombre científico con el que se concibe el producto es aceptado por la comunidad científica quien se encarga de identificarlo y categorizarlo, mientras que el nombre comercial se concibe con el fin de difundirlo entre el público en general y su denominación puede variar en las regiones del mundo donde sea distribuido, sin que ello incida en el cambio de sus componentes químicos. Igualmente sucede, tal y como veremos en el ejemplo (16), con las denominaciones que reciben ciertas enfermedades.

En síntesis, un mismo referente puede cambiar de una cultura a otra, de la misma manera que puede cambiar en el interior de una misma cultura. En este sentido, podemos afirmar que un mismo objeto se expresa mediante formas denominativas diferentes, porque el contenido de dicho objeto se percibe o bien se observa desde diferentes ángulos o puntos de vista. Así pues, podríamos decir que nos encontramos ante un subtipo de variación del que se puede dar cuenta mediante los principios de historicidad cultural, individual o colectiva.

Este fenómeno se ilustra de la siguiente manera: 
(16) Afflictions such as Parkinson's disease or amyotrophic lateral sclerosis (Lou Gehrig's disease) progressively rob control of the body.

Desde el punto de vista de la forma, tenemos igual número de tokens (3): amyothrophic lateral sclerosis (VDE1) [A+A+N], Lou Gehrig's disease (VDE2) [A+A+N].

Desde el punto de vista del contenido observamos que, por un lado, el autor presenta la denominación de la enfermedad en la que consta una mínima descripción de ésta, amyothrophic lateral sclerosis y, por otro lado, la denominación más específica en la que consta el nombre de la persona que la descubrió Lou Gehrig's disease.

En VDE1, el autor focaliza en los rasgos más específicos que describen la dolencia como una enfermedad neuromuscular en la que las células nerviosas, que controlan el movimiento muscular voluntario, gradualmente disminuyen su funcionamiento y mueren, provocando debilidad y atrofia muscular. Mientras que en VDE2, el autor focaliza en una de las personas que contribuyó a su descubrimiento, Lou Gehrig. Cabe resaltar que esta enfermedad también se conoce con el nombre de una de las personas que la ha padecido, a saber: [enfermedad de] Stephen Hawking. En VDE2, por tanto, no contamos con una descripción a fondo de la dolencia.

Al proponer estas dos variantes denominativas, el autor deja en evidencia su conocimiento específico y da a conocer un fenómeno o realidad desde puntos de vista diferentes, dirigidos a públicos, a nuestro modo de ver, con características diferentes.

En VDE1 amyothrophic lateral sclerosis, el autor se dirige a una comunidad abierta que en principio engloba la mayoría de la población y que, por sus experiencias comunes (valores, costumbres, etc) ampliamente compartidas (memoria colectiva), logran captar las características específicas de la enfermedad. La intención del autor en este caso es lograr que la mayoría de los miembros de la comunidad comprendan y, al mismo tiempo, difundan este conocimiento.

En VDE2 Lou Gehrig's disease, el autor se dirige a una comunidad específica que posee un conocimiento específico y que, aunque comparten cierto tipo de experiencias, éstas se reducen a prácticas de dominios específicos en los que prima el saber compartido sobre las costumbres y valores cotidianos. La intención del autor en este caso es otorgar reconocimiento, dentro de la misma comunidad científica, a un grupo específico que contribuye a desarrollar el conocimiento de un dominio especializado haciendo uso de este tipo de denominaciones.

A manera de síntesis, diríamos que en este subtipo de refocalización, la interacción que se presenta entre la forma y el contenido de cada una de las variantes denominativas, está estrechamente relacionado con las diferentes percepciones de una misma realidad, percepciones éstas que, además, están vinculadas a una realidad cultural.

\subsubsection{Refocalización interna}

En este subtipo de variación, tal y como hemos expresado anteriormente, las variantes denominativas presentan rasgos diferentes porque entre ellas se da una relación de inclusión. En la relación de inclusión, un objeto $X$ es parte de un objeto $Y$; e $Y$, a la vez, presenta características adicionales. Este hecho podría representarse de la siguiente forma ${ }^{\text {xii. }}$ :

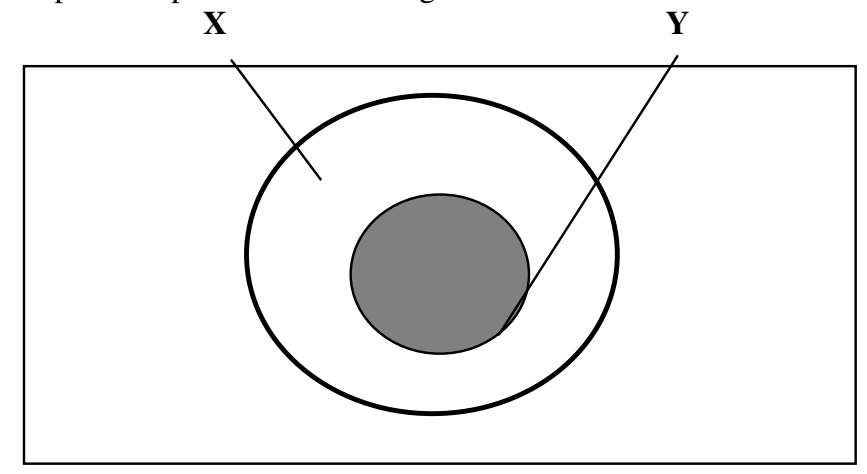

En otras palabras, la unidad léxica $X$ (VDE1) está contenida en la unidad léxica $Y$ (VDE2), y además, la unidad léxica $Y$ (VDE2) incluye uno o varios rasgos adicionales. La relación de inclusión ha sido ampliamente estudiada por diversos autores (Chaffin, Herrmann y Winston (1987), entre otros), quienes han tratado de analizarla dentro de las relaciones no meronímicas ${ }^{x i i}$ con el fin de calificar ciertos casos de inclusión próximos a la hiponimia.

Según Cruse (1986:168-171), la inclusión puede manifestarse en uno de los sentidos: la supermeronimia, meronimia más general que holonimia, es decir, establece relación sin ambigüedad con al 
menos otro holónimo (página-libro; nail-toe, en la que nail está en relación super-meronímica bilateral con toe).

La relación de hiponimia ${ }^{\text {xiv }}$ constituye una relación paradigmática que se establece entre un lexema más específico y otro más general, como ocurre en "vaca": "animal", "honradez": "virtud". El término hiponimia se ha creado para distinguir esta relación léxico-semántica de la de "inclusión" (implicación), utilizada en lógica. La formulación del tipo de relaciones de inclusión se basa en la noción de referencia. No obstante, la relación de hiponimia no es a veces totalmente clara. En efecto, una de las razones que justifican el empleo del término "hiponimia" es que la relación hiponímica, en contraste con la de inclusión, se aplica tanto a los términos que tienen referencia como a los que no la tienen.

De todas formas no está claro si un hipónimo está incluido en su hiperónimo, o viceversa. Si se atiende a la extensión de los lexemas habrá que decir que el lexema hiperónimo "flor" es más inclusivo que "tulipán", en el sentido de que incluye, además del tulipán, otros conceptos de flores, mientras que a partir de la intención sucede lo contrario. En término de implicación, la hiponimia se define como una implicación unilateral: X (VDE1) es un tulipán implica X (VDE1) es una flor; pero la implicación inversa no se mantiene en ningún caso.

La definición de hiponimia a base de la implicación unilateral permite, a su vez, definir la sinonimia mediante la implicación bilateral o simétrica: si VDE1 (X) es hipónimo de VDE2 (Y), y VDE2 (Y) es hipónimo de VDE1 (X), entonces VDE1 (X) y VDE2 (Y) son sinónimos.

La hiponimia es también una relación transitiva. Si VDE1 (X) es hipónimo de VDE2 (Y) y VDE2 (Y) es hipónimo de VDE3 (Z), entonces VDE1 (X) es hipónimo de VDE3 (Z). Por ejemplo, "vaca” es hipónimo de "mamífero" y "mamífero" lo es, a su vez, de "animal”, luego "vaca" es hipónimo de "animal".

En un estudio realizado sobre las relaciones conceptuales, Feliu (2000:45) subraya que dentro de las relaciones de inclusión podemos distinguir dos tipos: la inclusión topológica o espacial y la de clase o hiponimia. En la primera, la topológica o espacial, la relación se establece entre un contenedor, área o duración y aquello que contienen. En los casos de relación espacial, frecuentemente malinterpretados como casos meronímicos (relación lugar-área), un elemento está incluido en otro pero no constituye una parte de él (e.j. the liver is sorrounded by the body).

En el segundo tipo de inclusión, la de clase o hiponímia, la relación se establece entre un genérico y cualquiera de sus subordinados. Este tipo de relación se expresa mediante las siguientes predicaciones: VDE1 is type of VDE2; VDE1 is VDE2; VDE1 is a kind of VDE2; VDE1 is a VDE2.

En el siguiente ejemplo extraído de nuestro corpus, vemos claramente como algunas VDE mantienen entre sí una relación de inclusión:

(17) In both cases, the genes are usually first put into transporters, or vectors, able to deposit foreign genes into cells.

En el plano formal, observamos que las variantes tienen el mismo número de unidades (1) y la misma categoría gramatical [N].

Desde el plano del contenido, la VDE1 transporters hace referencia al "medio que utilizan los genes para trasladarse de un lugar a otro". La VDE2 vectors son también transporters pero, los vectores además permiten "la inserción de secuencias de ADN foráneas".

Observamos que en VDE1 el autor decide focalizar la atención en una de las principales funciones que cumplen los vectores: transporters. En este sentido, el autor ilumina la cara del poliedro que tiene que ver con una de las características que tiene VDE2. En VDE2, el autor recurre al procedimiento de terminologización y presenta la UT que hace referencia no sólo a la función que cumplen sino al objeto en sí: vectors, [una molécula de $\mathrm{ADN}$ ] con sus correspondientes características, [que puede replicar en el interior de una célula huésped y transportar...].

En el ejemplo, el autor presenta VDE1 desde un punto de vista más general y VDE2 desde un punto de vista más especializado. Decimos más especializado porque VDE2, vectors, ilumina rasgos que son propios del dominio de especialidad: muchos objetos X pueden ser transportadores; sin embargo, no se hace referencia a que muchos objetos X pueden ser vectores. La relación que establece el MVDE or es tanto de inclusión (trasnsporter forma parte de vector) como de exclusión (un vector cumple otro tipo de función).

Tal y como hemos observado en el análisis realizado sobre el tipo de caso denominado refocalización, los conceptos de poliedricidad (Cabré 1999) o punto de vista (Condamines 1997) están vinculados a una elección que realiza el productor del discurso, apoyado en una serie de elementos discursivos que forman parte de la micro y macroestructura del texto. Dicha elección puede ser individual (compete a un solo emisor) o colectiva (compete a un grupo de emisores).

"La situation de production n'est pas neutre, et ne peut être définie abstraitement. Elle prend toujours place dans une pratique sociale qui définit le discours dont relève le texte et le genre qui le structure" (Rastier 1995:13). 
En síntesis, en lo que concierne a la refocalización, podemos afirmar que no existe un único punto de vista desde el que se pueda definir linealmente la unidad terminológica como universalmente cierta.

En nuestro corpus hemos encontrado un total de 62 ocurrencias $(21 \%$ del total de casos de variación) que corresponden a los tipos de refocalización, de los cuales 36 (57\%) son refocalizaciones externas y $26(43 \%)$ son refocalizaciones internas.

La refocalización externa se manifiesta en el corpus acompañada de los siguientes MVDE: or $(58 \%)$, called $(25 \%)$, parenthesis $(8 \%)$, known as $(6 \%)$, referred to as $(3 \%)$. Los MVDE que introducen la refocalización interna en su respectivo orden de aparición son los siguientes: called (36\%), or (23\%), parenthesis $(23 \%)$, referred to as (15\%), known as (3\%).

Estos datos nos dan pie para pensar que los MVDE más utilizados por los productores discursivos para establecer una relación de refocalización son: or y called. Ambos marcadores contribuyen al emisor/emisores a plantear una misma realidad desde diferentes puntos de vista o caras del poliedro.

Los datos analizados muestran que de las 301 ocurrencias de variación denominativa explícita que forman parte de nuestro corpus de análisis, 184 son de tipo reducción (61\%), 62 pertenecen a la refocalización $(21 \%)$ y 55 son de tipo expansión (18\%).

Los resultados obtenidos a partir del análisis de los componentes semánticos de las VDE han permitido proponer una tipología de casos de VDE con sus respectivos subtipos que representamos, a manera de síntesis, en el siguiente cuadro:

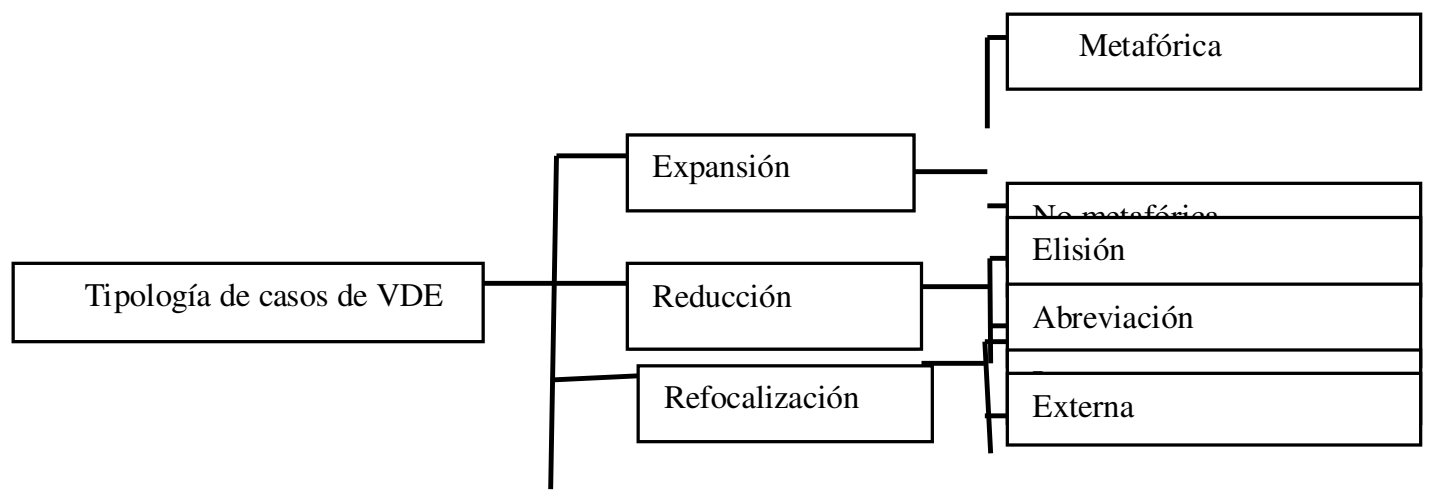

Figura 2. Propuesta de tipología de casos de VDE

\section{CONCLUSIONES}

A lo largo de esteartículo hemos demostrado que la relación semántica que mantienen las variantes denominativas explícitas no es una relación de equivalencia absoluta, sino que, existe entre ellas una relación de equivalencia parcial o relativa. El modelo de análisis adoptado, que considera elementos de la Teoría Comunicativa de la Terminología, ha permitido demostrar que la introducción de una variante denominativa o unidad léxica alternativa conduce casi siempre a un cambio no sólo formal sino también semántico en el interior del discurso especializado.

Para realizar el análisis de las variantes denominativas explícitas nos hemos valido del análisis de los componentes del contenido que permite establecer los rasgos o componentes comunes y diferenciales que hay entre las variantes denominativas explícitas (Nida 1975a, Gülich y Kotschi 1995). De esta manera, hemos podido determinar la relación semántica que mantienen las variantes entre sí.

Este tipo de análisis ha permitido establecer una tipología de casos de variación denominativa explícita. Dicha propuesta de tipologización se ha hecho en función del cambio semántico que se produce entre las variantes. En este cambio semántico, el marcador discursivo cumple un papel muy importante, puesto que contribuye a determinar la relación existente entre las variantes.

La propuesta tipológica planteada muestra que los cambios pueden manifestarse de forma diferente, bien sea porque se añaden o reducen rasgos o componentes formales y semánticos en las unidades léxicas, o bien porque dichas unidades se presentan desde diferentes puntos de vista o distintas caras del poliedro.

El primer tipo de caso identificado - adición de rasgos o componentes semánticos- corresponde a lo que hemos denominado expansión. La expansión puede situarse en un eje en el que se establece una relación que va desde la paráfrasis hasta la definición. Ambos tipos de relación son utilizados como estrategias discursivas con el fin de explicitar el contenido y de esta manera asegurar la comprensión del 
destinatario. Dentro de este tipo de variación hemos identificado dos subtipos que hemos denominado expansión metafórica y no metafórica.

La expansión a manera de explicación metafórica se utiliza con el fin de estructurar el conocimiento menos concreto en términos más concretos que estén relacionados directamente con la experiencia del destinatario.

La expansión a manera de explicación no metafórica se utiliza con el fin de comunicar al destinatario un determinado conocimiento especializado de manera efectiva y accesible. En general, podemos afirmar que la expansión se utiliza para evitar problemas de comunicación durante la interacción emisor/receptor y para verbalizar contenidos complejos y abstractos de manera simplificada

El segundo tipo de caso identificado en nuestro corpus de análisis —reducción de rasgos o componentes semánticos- corresponde a lo que hemos denominado reducción. Este tipo de caso se manifiesta en nuestro corpus mediante dos subtipos que hemos denominado reducción por elisión o abreviación. Ambos tipos de reducción tienen la finalidad de otorgar un mayor nivel de especialidad al texto, comunicar un conocimiento especializado de manera especializada y verbalizar contenidos simples de manera más compleja para un receptor no experto.

Hemos denominado el tercer tipo de caso refocalización - proceso mediante el cual las variantes denominativas se presentan desde diferentes puntos de vista-, fenómeno que tiene una relación directa con el concepto de poliedricidad propuesto desde el marco de la TCT. Dentro de este tipo, hemos identificado dos subtipos que hemos denominado refocalización externa y refocalización interna.

La refocalización externa está relacionada con la creatividad léxica y, por tanto, con los aspectos culturales que acompañan este proceso de creación. La refocalización interna tiene que ver con la relación de inclusión que presentan entre sí las unidades léxicas. Ambos tipos de refocalización permiten corroborar la idea de que no existe un único punto de vista desde el que se pueda definir la UT como universalmente válida. Estos datos nos dan pie para pensar que las UT son realmente poliédricas por cuanto pueden ser analizadas desde diferentes puntos de vista. Aspecto relevante que contribuye a corroborar no sólo la existencia de la variación denominativa en los textos especializados, sino el vínculo existente entre la creación léxica y la concepción de la realidad; la adquisición y transferencia de conocimiento por parte de los productores discursivos.

Los datos analizados muestran que de las 301 ocurrencias de variación denominativa explícita que forman parte de nuestro corpus de análisis, el 61\% (184 ocurrencias) son de tipo reducción, el 21\% (62 ocurrencias) pertenecen a la refocalización y el 18\% (55 ocurrencias) son de tipo expansión.

Este análisis también nos ha permitido comprobar el importante papel que juegan los marcadores de variación denominativa explícita en el análisis semántico de las variantes denominativas. Este marcador es una consecuencia del grado de equivalencia entre las variantes:

- Para el productor del discurso, el marcador es fruto de la conceptualización de similitud, mayor o menor, entre dos variantes.

- Para el analista, el marcador es una pista que contribuye a detectar el mayor o menor grado de equivalencia existente entre las variantes denominativas.

\section{BIBLIOGRAFÍA}

ADELSTEIN, A. (1998) "Condiciones de reductibilidad léxica de los sintagmas terminológicos", en: VI Simposio Iberoamericano de Terminología. La Habana (Cuba). [CD-ROM].

; KORNFELD, L.; KUGEL, I.; RESNIK, G. (2000) "Los sintagmas terminológicos en los textos de especialidad", en: Serie ponencias de la Primera Jornada Anual de Investigación de la Universidad Nacional de General Sarmiento. Argentina, Universidad Nacional de General Sarmiento, 3148.

ARNTZ, R.; PICHT, H. (1989) Einfürung in die Terminologiearbeit. Hildesheim: Olms. [Traducción castellana: ARNTZ, R.; PICHT, H. (1995) Introducción a la terminología. Madrid, Pirámide, Fundación Germán Sánchez Ruipérez].

BACH, C. (2001) Els connectors reformulatius catalans: anàlisi i proposta d'aplicació lexicogràfica. Tesis Doctoral Presentada al Institut Universitari de Lingüística Aplicada de la Universitat Pompeu Fabra.

; FREIXA, J.; SUÁREZ, M.M. (2000) "Equivalencia conceptual y reformulación parafrástica en terminología”, en: VII Simposio Iberoamericano de Terminología. Portugal (Lisboa). [CD-ROM].

BACH, C.; SUÁREZ, M.M. (2002) "La variación denominativo-conceptual en la traducción científicotécnica: el papel de la reformulación”, en: Universitat Pompeu Fabra (eds.). Proceedings of the 2nd International Conference on Specialized Translation. Barcelona (España), 119-127. 
CABRÉ, M.T. (1999) La terminología: Representación y comunicación. Una teoría de base comunicativa y otros artículos. Barcelona, Institut Universitari de Lingüística Aplicada, Universitat Pompeu Fabra. (Sèrie Monografies, 3).

163-199. (2003) “Theories of terminology. Their description, prescription and explanation”, 9:2, p.

CHAROLLES, M.G. (1984) "En réalité et en fin de compte et la résolution des options", en: Travaux du Centre de recherches sémiologiques, 47, 81-111.

CIAPUSCIO, G. (1993) "Reformulación textual: el caso de las noticias de divulgación científica", en: Revista argentina de lingüística 9/1-2, 69-117.

(2003) "Formulation and Reformulation Procedures in Verbal Interactions between

Experts and (Semi-) Laypersons", en: Discourse Studies, 5/2, London, SAGE publications, 207-234.

CONDAMINES, A.; REBEYROLLE, J. (1997) "Point de vue en langue spécialisée", en: Meta, 42/1, 174-184.

CORTÉS J.; MARTINEZ, A. (1996) Diccionario de filosofía en CD-ROM. Barcelona, Herder.

CRUSE, D.A. (1986) Lexical Semantics. Cambridge, Cambridge University Press.

DIKI-KIDIRI, M.; NOMDEDEU, A.; SUÁREZ, M.M. (en prensa) "Variation dénominative dans des textes scientifiques de vulcanologie”, en: DIKI-KIDIRI, M.; EDEMA, J. B. (eds.). La Terminologie Culturelle. Théorie, méthode et applications. París, Université de Paris VII.

FELIU, J. (2000) Relacions conceptuals i variació funcional: elements per a un sistema de detecció automática. Trabajo de investigación presentado en el Institut Universitari de Lingüística Aplicada, Universitat Pompeu Fabra, Barcelona.

FUCHS, C. (1982) La Paraphrase. París, Presses Universitaires de France. . (1994) Paraphrase et énonciation. París, Ophrys.

GÜLICH, E.; KOTSCHI, T. (1995) "Discourse production in oral communication", en: QUASTHOFF, U.M. (ed.) Aspects of Oral Communication, Research in Text Theory, 21. Berlín-New York, Walter de Gruyter, 30-66.

JAKOBSON, R. (1960) “Closing Statement: Linguistics and Poetics”, en: SEBEOK, T.A. (ed.). Style in Language. Cambridge, MIT Press, 350-377.

KLEIBER, G. (1984) "Dénomination et relations dénominatives", en: KOSKAS, E.; KREMIN, H. (eds.). Langages. La dénomination. París, Didier, 76, 77-94.

. (1990) La sémantique du prototype. París, Presses Universitaires de France.

LAKOFF, G.; JOHNSON, M. (1991) Metáforas de la vida cotidiana. Segunda edición, España, Cátedra Teorema.

MORTUREUX, M.F. (1984) "La dénomination: approche socio-linguistique", en: KOSKAS, E.; KREMIN, H. (eds.). Langages. La dénomination. París, 76, Didier, 95-112.

NENADIĆ, G.; SPASIĆ, I.; ANANIADOU, S. (2002) "Automatic Acronym Acquisition and Term Variation Management within Domain-Specific Texts", en: Proceedings of LREC-3. Las Palmas (Spain), 2155-2162.

NIDA, E. (1975) Componential Analysis of Meaning. La Haya, Mouton.

RASTIER, F. (1995) Realismo semántico y realismo estético. Valencia. Universidad de Valencia.

REY-DEBOVE, J. (1978) Le métalangue; étude linguistique du discours sur le langage. París, Le Robert. RIEGEL, M. (1987) "Définition directe et indirecte dans le langage ordinaire: Les énoncés définitoires copulatifs", en: Langue française 73, 29-53.

STRAWSON, P.F. (1973) Les individus, París, Seuil.

TRICÁS PRECKLER, M. (1995) Manual de traducción, francés-castellano. Barcelona, Gedisa.

WÜSTER, E. (1979) Einführung in die Allgemeine Terminologielehre und Terminologische Lexicographie. Viena, Springer [Traducción castellana: Introducción a la teoría general de la terminología y a la lexicografía terminológica. CABRÉ, M.T. (ed.) (1998). Barcelona, Institut Universitari de Linguiístic Aplicada, Universitat Pompeu Fabra]..

Notas:

${ }^{\mathrm{i}}$ Este artículo comprende los resultados obtenidos en la tesis doctoral titulada: análisis contrastivo de la variación denominativa en textos especializados: del texto original al texto meta, defendida en junio de 2004 en el marco del programa de doctorado de Lingüística Aplicada del Instituto Universitario de Lingüística Aplicada (IULA) de la Universidad Pompeu Fabra de Barcelona, bajo la dirección de M. Teresa Cabré. 


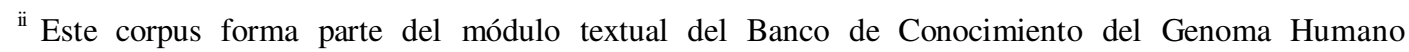
desarrollado por el grupo de investigación IULATERM del Instituto Universitario de Lingüística Aplicada de la Universidad Pompeu Fabra como resultado de dos proyectos: TEXTERM BFF2000-0841 y RICOTERM TIC2000-1191.

${ }_{\text {iii }}$ Con el fin de ilustrar el método de consulta utilizado para determinar los contenidos semánticos de las variantes denominativas, tomamos como base la propuesta de Cabré (1999) sobre la teoría de las puertas en la que se plantea que entrar en la terminología de un campo de conocimiento interdisciplinar supone elegir una puerta de entrada puesto que el objeto de estudio de la disciplina —el término- es una unidad al mismo tiempo semiótica, lingüística, cognitiva y social que puede ser tratada desde y por diferentes disciplinas.

${ }^{\text {iv }}$ Los componentes comunes se expresan a través del signo [+] y los componentes diferenciales mediante el signo [-].

${ }^{v}$ Es importante resaltar que tanto Gülich \& Kotschi como Ciapuscio trabajan desde la perspectiva de la producción discursiva y se interesan ante todo por el tema de la reformulación en textos de divulgación. Aunque la publicación de Gülich \& Kotschi aparece dos años después de Ciapuscio (1993), dejamos constancia que los investigadores han trabajado conjuntamente y es Ciapuscio quien retoma la clasificación planteada por Gülich \& Kotschi.

${ }^{v i}$ En su trabajo, Bach (2001) propone una tipología de marcadores reformulativos para el catalán.

vii Las referencias presentadas corresponden al Diccionario de filosofía en CD-ROM (1996)

viii Para mayor información sobre el papel de los marcadores en la VDE, véase Bach \&Suárez (2002)

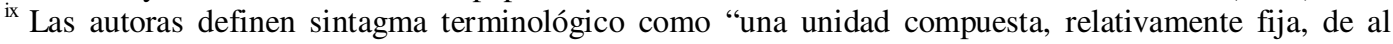
menos dos unidades gráficamente simples, susceptible de ocupar en la frase una posición de constituyente sintáctico mínimo autónomo y que es la denominación de un concepto comprendido en el sistema conceptual de un dominio de especialidad" Adelstein et al., (2000:36).

${ }^{\mathrm{x}}$ La cita a la que hacemos mención está en Kleiber (1984).

${ }^{x i}$ Véase Bach et al (2002).

xii Representación de la relación de inclusión propuesta por Arntz \& Picht (1995:192).

xiii "La relación de meronimia es un tipo de relación descrita por Wüster como una relación ontológica que presenta problemas de identificación y generación. Según la norma ISO/704 "una relación parte-todo constituye la relación entre un todo y sus partes". (en Feliu, J. 2000:38).

${ }^{\text {xiv }}$ Cortés Morató, J y Martínez Riu, A, Diccionario de filosofía en CD-ROM (1996). 